\title{
THE FUNCTION OF ADIPSIN AND C9 PROTEIN IN THE COMPLEMENT SYSTEM IN HIV-ASSOCIATED PREECLAMPSIA
}

By

\section{MIKYLE DAVID}

Submitted in partial fulfilment for the degree of

\section{Master in Medical Science}

in the

Discipline of Optics and Imaging

Doris Duke Medical Research Institute

College of Health Sciences

University of KwaZulu-Natal

South Africa

2020 


\section{PREFACE}

This study represents original work by the author and has not been submitted in any other form to another University. Where use was made of the work of others, it has been duly acknowledged in the text.

The research described in this dissertation was carried out in the Optics and Imaging Centre, Doris Duke Medical Research Institute, College of Health Sciences, University of KwaZu1uNatal, Durban, South Africa, under the supervision of Professor T. Naicker and Professor J. Moodley.

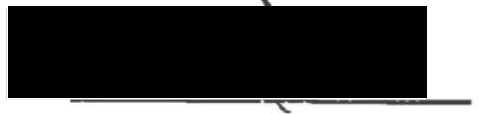

Mikyle David

(Student number:216000603)

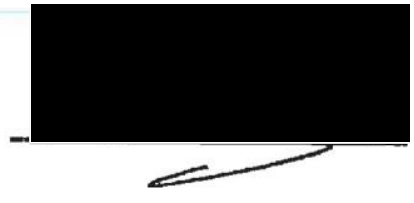

Professor Thajasvarie Naicker (Supervisor)

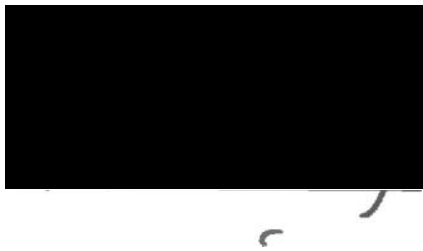

Professor Jagidesa Moodley (Co-Supervisor) 


\section{DECLARATION}

1, Mikyle David (216000603) declare that:

(i) The research reported in this dissertation is my original work, except where otherwise stated.

(ii) This dissertation does not contain another person's data, graphs pictures or infonnation, unless specifically acknowledged as being sourced from other researchers. Where other sources have been quoted, then:

(a) Their words have been paraphrased, but the general information attributed by them has been referenced.

(b) Where their exact words were used, their writing was placed between quotation marks and referenced.

(iii) The dissertation has not been submitted for any degree or examination at any other institution,

(iv) Where I have produced a publication of which I am an author or co-author, I have indicated in detail which part of the publication was written by myself and have fully referenced such publications.

(v) This dissertation does not contain text, graphics or tables which were copied and pasted directly from other sources, unless specifically acknowledged and the source being detailed in the dissertation and reference section.

Signed:

Date: $\underline{30 / 11 / 20}$ 


\section{DEDICATION}

To my parents,

You have educated and supported me throughout all my endeavours

Thank you both 


\section{FUNDING}

Funding for this project was received from:

1. NRF Postgraduate Scholarship

2. Publication funds, Prof T Naicker 


\section{ACKNOWLEDGEMENTS}

I wish to offer my sincere gratitude to all who provided assistance and motivation throughout the course of this study. Special gratification is extended to:

- Professor T. Naicker who has guided, supported and motivated me through this journey.

- The Optics \& Imaging Centre for the use of their laboratory and samples.

- Miss Y. Pillay and Miss S. Padayachee for their assistance in the laboratory

- Miss W. Kelmemi for her technical assistance. 


\section{ETHICAL APPROVAL}

This study was approved by the Biomedical Research Ethics Administration, University of KwaZulu-Natal, Durban, South Africa. Ethics No: BCA 338/17. 


\section{TABLE OF CONTENTS}

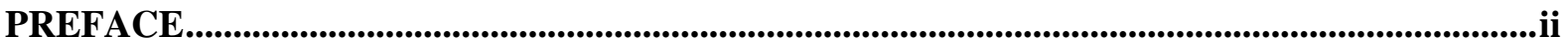

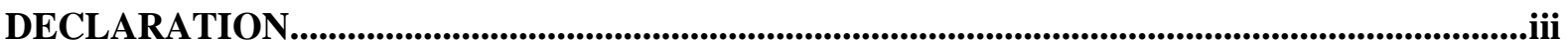

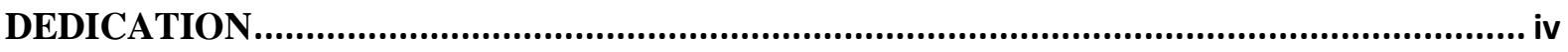

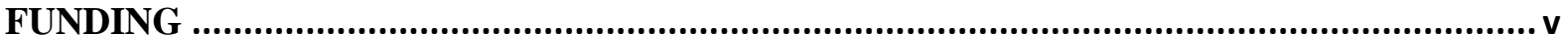

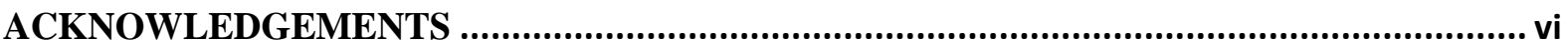

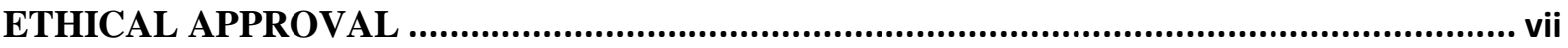

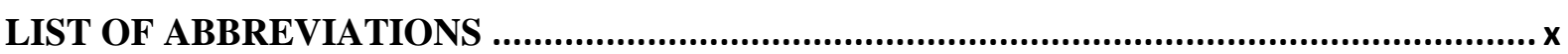

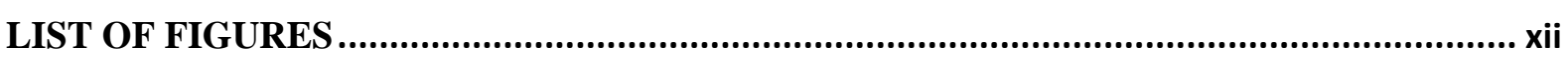

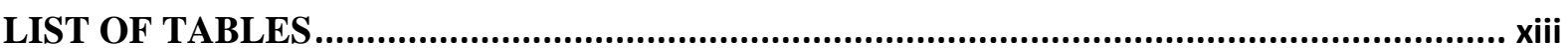

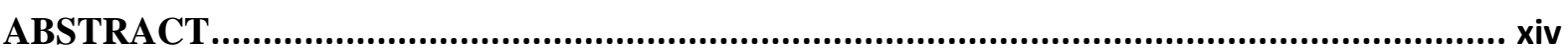

LITERATURE AND BACKGROUND REVIEW ......................................................... 1

1.1 HYPERTENSIVE DISEASE OF PREGNANCY AND PREECLAMPSIA ........................ 1

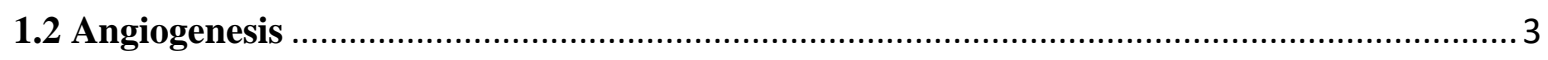

1.3.1 Highly Active Anti-Retroviral Therapy (HAART) in PE....................................... 4

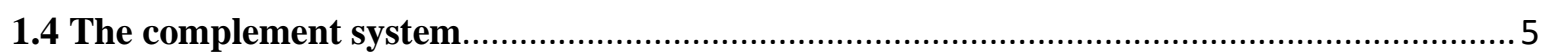

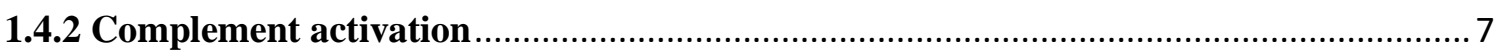

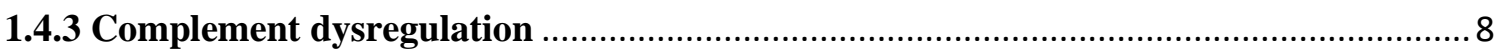

1.4.4 The complement system in normal and preeclamptic pregnancy- a summary ............. 9

1.4.5 The complement system and angiogenic imbalance ................................................... 10

1.4.6 The complement system in the duality of HIV infection and Preeclampsia ................. 10

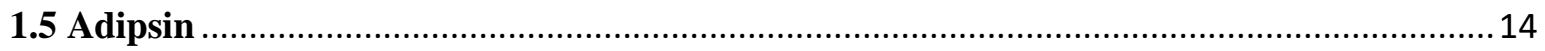

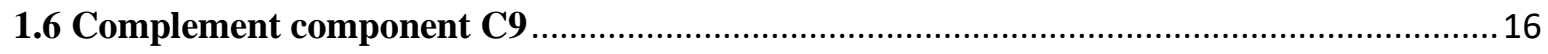

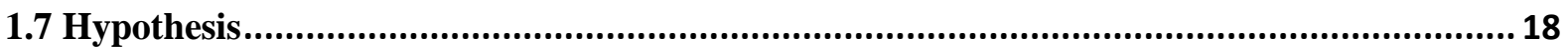

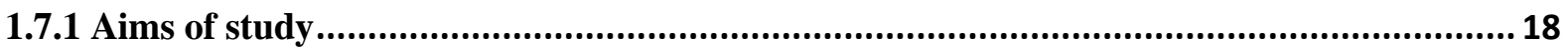

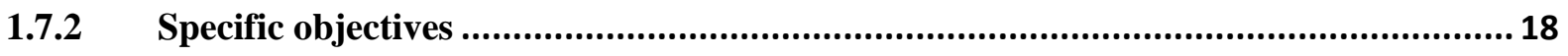

CHAPTER 2

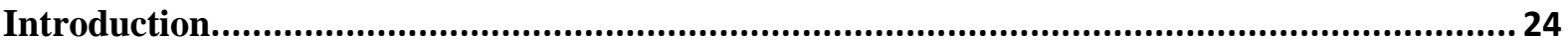

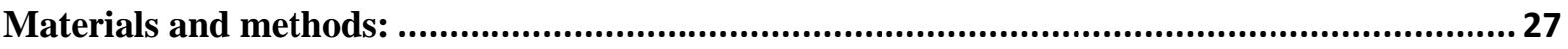

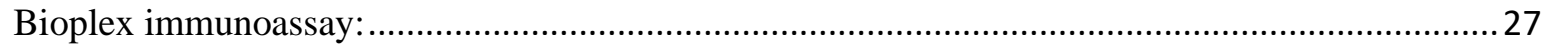

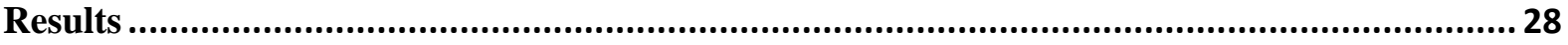

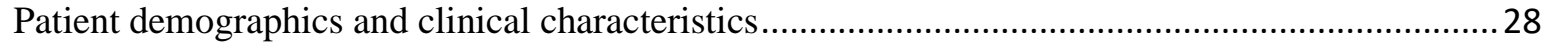

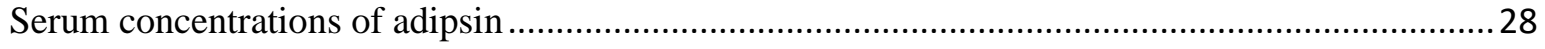

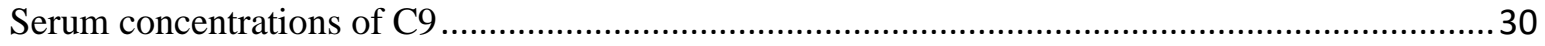

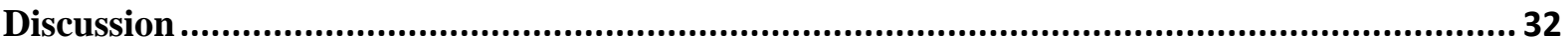

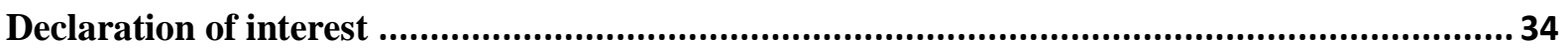




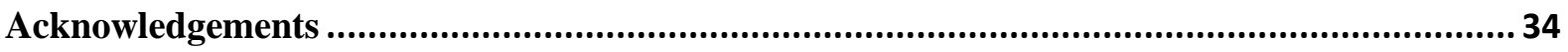

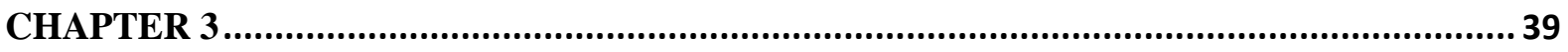

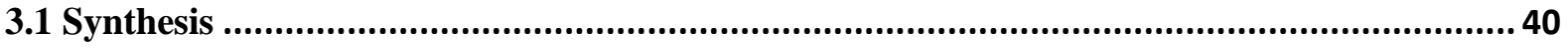

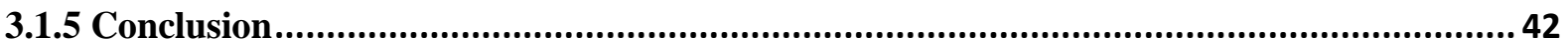

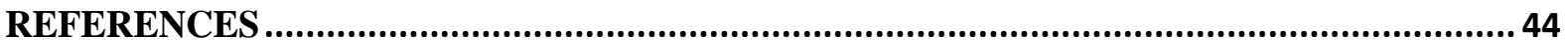

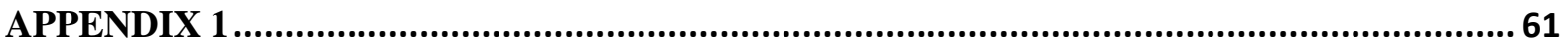

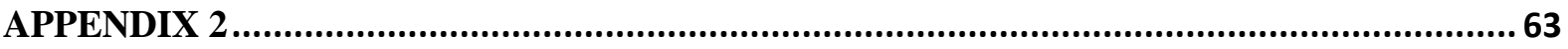

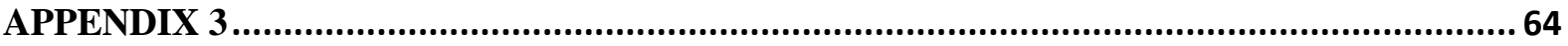




\section{LIST OF ABBREVIATIONS}

HDP

Hypertensive Disorders of Pregnancy

HIV Human immunodeficiency virus

PE

Preeclampsia

WHO

World Health Organization

EOPE Early onset preeclampsia

LOPE Late onset preeclampsia

EVT. Extravillous trophoblast cells

sEng Soluble endoglin

sFlt-1 Soluble fms-like

TH1 T-helper 1

TH2 T-helper 2

TNF- $\alpha$ Tumour necrosis factor

IL Inter-leukin

PIGFs Placental growth factors

VEGFs Vascular endothelial growth factors

NK Natural killer

HAART Highly active antiretroviral therapy

PIs Protease inhibitors

$\mathrm{CP}$ Classical Pathway

LP

Lectin Pathway

AP

Alternative Pathway

MAC

Membrane attack complex

BMI

Body mass index 
Tregs................................... Regulatory T cells

DCs................................... Dendritic cells

gp

Glycoprotein

MBL

Mannose-binding lectin 


\section{LIST OF FIGURES}

PAGE NO.

\section{CHAPTER 1}

Figure 1.1: $\quad$ Schematic overview of the complement system

Figure 1.2: $\quad$ Schematic diagram on the role of the complement system during HIV

Infection

Figure 1.3: $\quad$ Schematic diagram on the role of the complement system in preeclampsia

Figure 1.4: $\quad$ Illustration of the action of Adipsin

Figure 1.5: $\quad$ Schematic diagram on the function of complement component C9

\section{CHAPTER 2}

Figure 1: $\quad$ The serum concentrations of Adipsin

Figure 2: $\quad$ The serum concentrations of C9 


\section{LIST OF TABLES}

PAGE NO.

\section{CHAPTER 2}

Table 1: Demographic data and clinical profile of participants across all study groups 


\begin{abstract}
Background

Hypertensive disorders of pregnancy (HDP) and non-pregnancy related diseases (HIV, TB) are the most common causes of maternal mortality in South Africa (SA). Preeclampsia (PE), a complex medical disorder, accounts for the majority of maternal deaths emanating from HDP. In SA, the prevalence of HIV infection in pregnancy is high. The complement system, a part of our innate response, may be altered in the synergy of HIV infection and PE development. Complement activation at the maternal-interface may exacerbate inflammation, tissue injury, apoptosis as well as vascular leakage, in the complicated state of PE. The complement proteins, adipsin and $\mathrm{C}$, activates the body's natural defence against HIV infection. C9 functions as a pore-forming component of the membrane attack complex. Moreover, the high rollout in SA of antiretroviral therapy may affect the immune response in HIV infected women. This study investigates the concentration of the complement proteins, Adipsin and C9 in the duality of HIV-associated PE.
\end{abstract}

\title{
Method
}

Samples of 38 normotensive and 38 preeclamptic patients, stratified further by HIV status were collected from a regional hospital. Thereafter, analysis of analytes via the Bio-plex Multiplex immunoassay occurred.

\section{Results}

Maternal weight did not differ $(p=0.1196)$ across the study groups. The concentration of adipsin was statistically different between the PE vs normotensive pregnant groups, irrespective of HIV status $(p=0.0439)$. There was no significant difference in adipsin concentration between HIV-negative vs HIV-positive groups, irrespective of pregnancy type $(p=0.6290)$. Additionally, there was a significant difference in adipsin concentration between HIV negative normotensive $v s$ HIV negative preeclampsia $(p<0.05)$, as well as a difference between HIV negative preeclampsia $v s$ HIV positive preeclampsia $(p<0.05)$. C9 protein expression was not statistically different between the normotensive and PE groups, regardless of HIV status ( $p=0.5365$ ). No statistical significance in C9 expression was found between HIV positive $v s$ HIV negative groups, regardless of pregnancy type $(p=0.3166)$. Similarly, no statistical significance was noted across all study groups $(p=0.0774)$. 


\section{Conclusion}

This study demonstrates a significant up-regulation of adipsin in PE compared to normotensive pregnancies; this finding correlates with the exaggerated inflammatory milieu of PE. Complement C9 protein was similar between pregnancy types. This similarity may emanate from properdin dysregulation or a genetic polymorphism. The concentration of adipsin and C9 proteins were not affected by HIV status due to the immune reconstitution effect of antiretroviral therapy. Furthermore, the up-regulation of adipsin in placental sites and urinary levels of PE in previous studies, in tandem with our findings, indicate the possibility of adipsin as a predictor value for PE development. 


\section{ABSTRACT IN ISIZULU}

\section{Ingemuva}

Ukuphazamiseka ngokweqile kokukhulelwa (i-HDP) kanye nezifo ezingahlobene nokukhulelwa (i-HIV, i-TB) yizimbangela ezivame kakhulu zokufa komama eNingizimu Afrika (SA). I-Preeclampsia (PE) inkinga eyinkimbinkimbi yezokwelapha, ilandisa ngokufa komama abaningi okuvela ku-HDP. ENingizimu Afrika, izinga lokutheleleka nge-HIV ngesikhathi sokukhulelwa liphezulu. Uhlelo lokuncoma, oluyingxenye yokuphendula kwethu okungokwemvelo, lungaguqulwa ekubambisaneni kokutheleleka nge-HIV kanye nokuthuthuka kwe-PE. Gcwalisa ukusebenza ku-interface yomama kungakhuphula ukuvuvukala, ukulimala kwezicubu, i-apoptosis kanye nokuvuza kwemithambo, esimweni esiyinkimbinkimbi se-PE. Amaprotheni agcwalisa, i-adipsin kanye ne-C9 kusebenze ukuzivikela kwemvelo komzimba ekuthelelekeni nge-HIV. Imisebenzi ye-C9 njengengxenye yokwakha i-pore yenkimbinkimbi yokuhlasela kwe-membrane. Ngaphezu kwalokho, ukukhishwa okuphezulu eSA kwemishanguzo kungathikameza amasosha omzimba kwabesifazane abane-HIV. Lolu cwaningo luphenya ukugxila kwamaprotheni ahambisanayo, i-Adipsin kanye ne-C9 kubumbili be-PE ehlobene ne-HIV.

\section{Amasampula}

ezingama-38 ze-normotensive kanye nama-38 preeclamptic, ahlukaniswe ngokwengeziwe nesimo se-HIV aqoqwa esibhedlela sesifunda. Ngemuva kwalokho, ukuhlaziywa kwamaanalytics nge-Bio-plex Multiplex immunoassay kwenzeka.

\section{Imiphumela}

Isisindo somama asihlukile ( $\mathrm{p}=0.1196)$ kuwo wonke amaqembu okufunda. Ukuhlushwa kweadipsin kwakwehluke ngokwezibalo phakathi kwamaqembu e-PE vs normotensive abakhulelwe, kungakhathalekile isimo se-HIV ( $\mathrm{p}=0.0439)$. Kwakungekho mehluko ophawulekayo ekugxileni kwe-adipsin phakathi kwamaqembu angenayo i-HIV noma i-HIV, kungakhathalekile uhlobo lokukhulelwa $(\mathrm{p}=0.6290)$. Ngokwengeziwe, bekunomehluko omkhulu ekugxileni kwe-adipsin phakathi kwe-HIV negative normotensive vs HIV negative preeclampsia ( $\mathrm{p}<0.05$ ), kanye nomehluko phakathi kwe-HIV negative preeclampsia vs HIV positive preeclampsia ( $\mathrm{p}<0.05$ ). Isisho seprotheyini se-C9 sasingafani ngokwezibalo phakathi kwamaqembu we-normotensive nama-PE, ngaphandle kwesimo se-HIV ( $p=0.5365)$. Akunakubaluleka kwezibalo ekuvezweni kwe-C9 okutholakele phakathi kwamaqembu ane- 
HIV noma amaqembu angenayo i-HIV, ngaphandle kohlobo lokukhulelwa $(\mathrm{p}=0.3166)$. Ngokufanayo, akukho ukubaluleka kwezibalo okwaphawulwa kuwo wonke amaqembu okufunda $(\mathrm{p}=0.0774)$.

\section{Isiphetho}

Lolu cwaningo lukhombisa ukulawulwa okuphezulu kwe-adipsin ku-PE uma kuqhathaniswa nokukhulelwa okujwayelekile, lokhu kutholakala kuhambelana nendawo evuthayo yokuvuvukala ye-PE. Ukugcwalisa amaprotheni we-C9 ayefana phakathi kwezinhlobo zokukhulelwa. Lokhu kufana kungavela ekushayweni kwe-efaneledin, noma i-polymorphism yofuzo. Ukuhlungwa kwamaprotheni e-adipsin nama-C9 akuzange kuthinteke isimo se-HIV, ngenxa yomphumela wokwakhiwa kabusha kwamasosha omzimba okwelashwa

ngezidambisigciwane. Ngaphezu kwalokho, ukulawulwa okuphezulu kwe-adipsin kumasayithi we-placental namazinga we-urinary we-PE ezifundweni ezedlule, ngokuhambisana nokutholakele kwethu, kukhombisa ukuthi kungenzeka yini ukuthi i-adipsin njengenani lesibikezelo sokuthuthuka kwe-PE. 
CHAPTER 1 


\section{LITERATURE AND BACKGROUND REVIEW}

\subsection{HYPERTENSIVE DISEASE OF PREGNANCY AND PREECLAMPSIA}

Hypertensive disorders of pregnancy (HDP) and non-pregnancy related diseases (HIV infection, TB) are the most common causes of maternal mortality in South Africa (Moodley et al., 2019). Hypertensive disorders of pregnancy account for approximately $18 \%$ of all maternal deaths in South Africa (Moodley et al., 2018). In developed countries, the prevalence of HDP is low (5-10\%) compared to developing countries (Naicker et al., 2019). Preeclampsia (PE) is a complex HDP that accounts for 500000 fetal and neonatal deaths and approximately 70000 maternal deaths worldwide (Gathiram and Moodley, 2016). The World Health Organisation (WHO) reports the prevalence of PE to be $1.6 \%$ in developed countries compared to $1.8-16.7 \%$ in developing countries (WHO., 2017). Preeclampsia is diagnosed by new-onset hypertension (BP $\geq 140 \mathrm{mmHg}$ or $\geq 90 \mathrm{mmHg}$ diastolic) after 20 weeks of gestation, with/without proteinuria ( $\geq 300 \mathrm{mg}$ ) (Brown et al., 2018). It is accompanied by maternal organ dysfunction and severe maternal complications that may include-the liver, kidney, etc. and hemolysis, elevated liver enzymes, and low platelet count referred to as the "HELLP" syndrome (Phipps et al., 2016; Brown et al., 2018)

Preeclampsia is a heterogeneous disease and may be divided into two main subtypes, viz., early and late-onset PE (Staff et al., 2013). The clinical signs for early-onset PE (EOPE) occur before 33 gestational weeks of pregnancy, and late-onset PE (LOPE) appears after 34 weeks of gestation. Late-onset PE constitutes the majority (>80\%) of preeclamptic cases (Gathiram and Moodley, 2016). The early-onset type is associated with abnormal placentation and correlates with high maternal and fetal morbidity and mortality rates (Von Dadelszen et al., 2003).

The pathogenesis of PE is not fully understood as yet. However, a common implication is the inadequate spiral uterine artery remodelling due to the inadequate migration of extravillous trophoblast (EVT) cells (McNally et al., 2017). During normal pregnancy, the trophoblast begins migration from the tips of anchoring villi through the decidua and the myometrium accompanied by spiral artery remodelling (Maître, 2017). The migration or proliferation of the EVT cells depends on the oxygen gradient established during placental development (Huppertz et al., 2009). In PE, this shallow trophoblast invasion and the failed transformation of the myometrial spiral arteries emanates from elevated apoptosis of trophoblast cells (Naicker et $a l ., 2013)$. This inadequate remodelling leads to the reduced diameter of spiral arteries and, 
therefore, lack of nutrients and oxygen supply to the placenta and developing fetus (Li et al., 2015). As a result, the placenta becomes ischemic and releases anti-angiogenic factors such as soluble endoglin (sEng), soluble fms-like (sFlt-1) and inflammatory mediators into the general circulation (Tomimatsu et al., 2017).

During normotensive pregnancies, multiple adaptations of the innate and adaptive immune systems are implemented to establish survival of the fetal allograft (Pierik et al., 2019), whilst simultaneously protecting mother and fetus from various pathogens (Hsu and Nanan, 2014).

Crucial immune adaptations are required to prevent fetus rejection and to provide protection against invading pathogens. In normal pregnancies, this is accomplished by causing a shift of the maternal response from T-helper 1 (TH1) type to a T-helper 2 (TH2) type immune response, which favours an immuno-tolerant microenvironment (Alrahmani, 2018; Perez-Sepulveda et al., 2014).

In PE, there is deficient development of maternal tolerance to the fetus or an altered maternal immune response due to excessive activation of neutrophils and monocytes (Saito et al., 2007). Notably, monocytes synthesise considerable amounts of pro-inflammatory chemokines and cytokines (Laresgoiti-Servitje, 2010; Perez-Sepulveda et al., 2014). Additionally, CD8+, CD4+ and dendritic cells also escalated the pro-inflammatory response (Jabbour et al., 2009).

Cytokines are immune modulators, and evidence suggests it plays a vital role in placentation, ovulation, implantation, and parturition (Bowen et al., 2002). Additionally, they are mediators of numerous cell signalling pathways and are synthesised by (Th1)-type and (Th2)-type immune cells, which exert positive and negative effects during pregnancy (Sargent et al., 2006). They assist in proliferation, angiogenesis, and placental invasion (Keelan and Mitchell, 2007) and are classified as pro-inflammatory (TNF- $\alpha$, IL-6) and anti-inflammatory (IL-4, IL10) cytokines (Sargent et al., 2006). The pro-inflammatory cytokines increase vascular permeability and also induces apoptosis of trophoblast cells (Chen et al., 2010). Furthermore, they also activate and damage endothelial cells, exacerbating the exaggerated inflammatory response seen in PE development (Granger, 2004; Kharfi et al., 2003). Off note, antiinflammatory cytokines are essential for the functioning of (Th2) and regulatory $\mathrm{T}$ cells, and this helps ensure a successful pregnancy (Thaxton and Sharma, 2010). Any imbalance in the levels of pro-inflammatory or anti-inflammatory cytokines may affect several immunological and apoptotic pathways, resulting in PE and other pregnancy-related disorders (Roberts, 2003). 


\subsection{Angiogenesis}

Angiogenesis is the process by which endothelial cells form new blood vessels from preexisting blood vessels by means of differentiation, migration and development (Kubis and Levy, 2003). Angiogenesis is initiated by placental growth factors (PIGFs) and pro-angiogenic vascular endothelial growth factors (VEGFs) (Steinberg et al., 2009), which function to encourage proteolysis of extracellular matrix and increase the vessel permeability, resulting in endothelial cell proliferation (Mutter and Karumanchi, 2008).

During angiogenesis, there are several factors that are believed to disrupt this process, viz., activation of natural killer (NK) cells and macrophages, and oxygen tension (Alain and Raouf, 2010). This activation causes a shift in the balance of angiogenic versus anti-angiogenic factors that culminate in endothelial dysfunction (Wallace et al., 2014). Aberrations in the angiogenic balance contribute to inadequate trophoblast invasion observed in PE (Maynard and Karumanchi, 2011).

According to Helmo et al., (2018), an increase in the expression of sFlt-1 kinase receptor and soluble endoglin with a concomitant decrease in the expression of VEGF and PIGF, impairs angiogenesis and vasculogenesis in PE. In HIV-1 infected patients, the process of angiogenesis is also dysregulated (Paydas et al., 2009). Adverse birth outcomes are elevated and have been associated with antiretroviral therapy (ART), compared to HIV-uninfected women (Chen et $a l .$, 2012). In a study carried out by Powis et al., (2013), angiogenesis was evaluated in preeclamptic women who began HAART administration during pregnancy. Women who developed PE, show an increase in anti-angiogenic factors, prior to HAART usage. Notably, Conroy et al., (2017), found a correlation between altered angiogenesis and ARV usage in the second and third trimester as a progenitor of preterm birth, stillbirth and small for gestational age, factors maternal factors characteristic of PE development.

\subsection{HIV Infection}

Human immunodeficiency virus is a retrovirus that invades a host and impairs cellular immunity, thereby increasing the hosts' susceptibility to opportunistic pathogens (Maartens et al., 2014). HIV infection remains a global pandemic, with 37.9 million people living with and 1.7 million people newly infected with HIV at the end of 201. South Africa has a population of 7.97 million people (13.5\%) infected with HIV (SA Stats, 2019), of which 4.7 million are 
women in their reproductive age (UNAIDS, 2020). Around $30 \%$ of South African women who are pregnant are infected with HIV (Kalumba et al., 2013), with the province of KwaZuluNatal having a prevalence of approximately $40 \%$. The association between HIV infection and $\mathrm{PE}$ in pregnancy originates from opposing immune responses, as PE induces an exaggerated immune response, whilst HIV dampens the immune response (Kalumba et al., 2013). However, this neutralisation is prevented by anti-retroviral therapy (ARVs) usage.

\subsubsection{Highly Active Anti-Retroviral Therapy (HAART) in PE}

The province of KZN has the highest ARV enrolment in the world (Kalumba et al., 2013). Exploiting the life cycle of HIV has led to the development of a combination of at least three ARV drugs, one of which is HAART (Reshi and Lone, 2010). Once HAART is initiated, the virus in the CD4+ T cells is suppressed in two phases: the early rapid phase occurring after 23 months of HAART usage and a slow delayed phase (Reshi and Lone, 2010). This causes a drop in the plasma HIV viral load count.

During pregnancy, HAART has the ability to decrease maternal viral replication and mother to child transmission, by reducing the plasma viral load in pregnant women (Siegfried et al., 2011). This suggests that HIV may neutralise the hyper-reactivity of the immune system associated with PE, hence reduce the risk of PE development (Govender et al., 2013). However, HAART re-establishes the immune response, thus increasing the risk for PE development (Landi et al., 2014).

HIV suppresses the immune response, and thus neutralises the hyper-inflammatory response of PE (Govender et al., 2013). In contrast, a greater risk for PE development can arise from the chronic arterial dysfunction with endothelial damage, associated with HIV infection (Fourie et $a l ., 2011)$. Nonetheless, the endothelial damage and vascular dysfunction caused by HAART administration have been reported to predispose patients to develop hypertensive disorders (Kline and Sutliff, 2008).

In the study conducted by Sansone et al., (2016) to determine the risk of PE in HIV-infected pregnant women receiving HAART, it was reported that $\mathrm{HIV}$-infected women and those receiving HAART, had a higher risk for PE development. However, more research needs to be done on this, as there are contradicting results on the risk of PE development on HAART administration (Kline and Sutliff, 2008). 
The prevalence of PE in HIV-infected pregnancies is lower; however, HAART administration may cause an upregulation of anti-angiogenic factors, endothelial dysfunction, and decreased nitric oxide (Aouache et al., 2018). Additionally, HIV infected pregnant women on HAART, showed an increase in the Th1 immune response (Maharaj et al., 2017), thereby increasing the risk of PE development increases (Kalumba et al., 2013; Sansone, 2016). The reasoning behind the higher risk of PE development by HAART usage is not yet fully understood. However, it is plausible that HAART may induce PE due to a direct toxic effect on the liver and kidney (Mawson, 2003). Additionally, HAART usage is documented to improve maternal immune remodelling (Suy et al., 2006), by restoring the mother's immune response to fetal antigens and subsequently making HIV-infected women more likely to develop PE (Mol et al., 2016).

Protease inhibitors (PIs) are potent anti-angiogenic factors. They deter HIV aspartyl protease and, the production of HIV, to promote immune restoration. Anti-retroviral therapy was also shown to lead to endothelial dysfunction by decreasing nitric oxide, resulting in induced endothelial oxidative stress (Chai et al., 2005), observed during the pathophysiology of PE development (Aouache et al., 2018).

\subsection{The complement system}

The complement system forms part of the innate immune system and consists of numerous plasma and cell membrane proteins (Merle et al., 2015). The complement system is initiated by three main pathways (figure 1.1) viz., the classical pathway (CP), the lectin pathway (LP), and alternative pathway (AP), which culminates into one common pathway (Noris and Remuzzi, 2013). The function of the complement system is the opsonisation of target surfaces, induction of pro-inflammatory responses, and the lysis of cells and pathogens. It is also vital in defence of the host by clearing apoptotic cells, injured tissue, and immune complexes, thus contributing to maintaining homeostasis (Lokki et al., 2014).

The $\mathrm{CP}$ is activated due to binding of recognition molecules $\mathrm{C} 1 \mathrm{q}$ to $\operatorname{IgG}$ or $\operatorname{IgM}$ immune complexes bound on the surface of microbes or other structures (McDonald et al., 2015). This causes a configurational change, resulting in the activation of $\mathrm{C} 1 \mathrm{r}$ and $\mathrm{C} 1 \mathrm{~s}$ (Noris and Remuzzi, 2013). Thereafter, $\mathrm{C} 1$ s cleaves $\mathrm{C} 4$ and $\mathrm{C} 2$ to form a $\mathrm{C} 4 \mathrm{bC} 2 \mathrm{~A}$ complex, which is a $\mathrm{C} 3$ convertase (Regal et al., 2015). The LP is activated by recognition molecules, viz., mannosebinding lectin (Conroy et al., 2017; Noris and Remuzzi, 2013) when they bind to mannose and sugar molecules on the surface of numerous microorganisms (Killick et al., 2018). This 
activates the LP serine protease MASP-1 and MASP-2, which then cleaves C4 and C2 to form C3 convertase, C4bC2a (Regal et al., 2017). The AP is different from the CP and LP, as it is continuously activated at low levels in the body (Merle et al., 2015). It is activated by the spontaneous hydrolysis of $\mathrm{C} 3$ to form $\mathrm{C} 3(\mathrm{H} 2 \mathrm{O})$, resulting in binding of factor B and cleavage of factor D to form C3 convertase, C3bBb (Schmidt et al., 2016).

All pathways of the complement system create $\mathrm{C} 3$ convertase, which split $\mathrm{C} 3$ into components, C3a, and C3b (Denny et al., 2013). C3b binds to the activating surface of its target and contributes to the activation of C5 convertase. C5 convertase cleaves C5 into C5a and C5b. C5b forms together with $\mathrm{C} 6, \mathrm{C} 7, \mathrm{C} 8$, and $\mathrm{C} 9$ to form the membrane-attack-complex (MAC), as seen in figure 1, to cause cell lysis (Denny et al., 2013; Tincani et al., 2010).

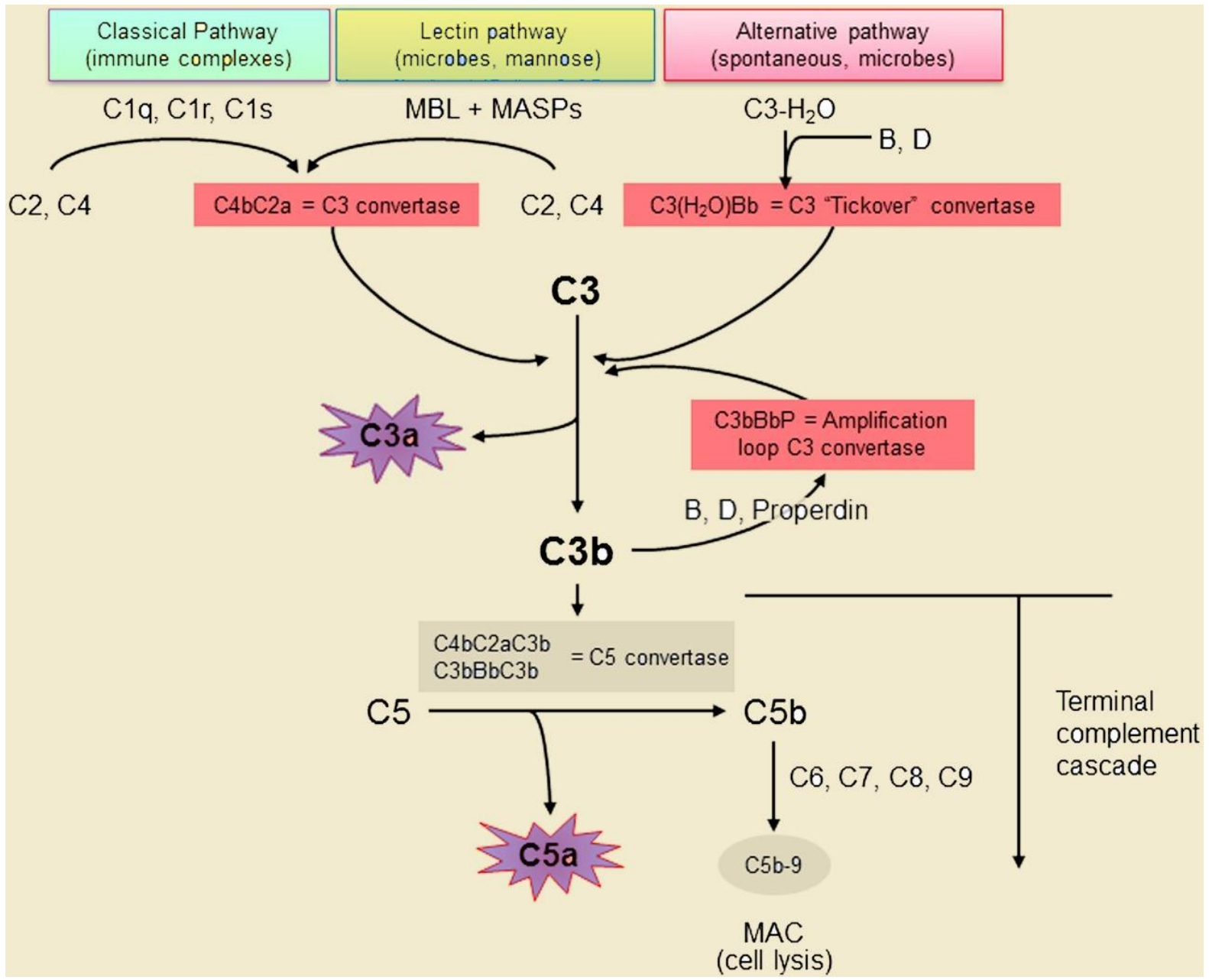

Figure 1.1: Schematic Overview of the complement system, illustrating the three pathways. Activation of the complement cascade occurs via three pathways viz., the classical, lectin and alternative pathway. All three pathways result in C3 convertase being produced, which cleaves C3 into C3a and C3b. Adapted from (De Vriese et al., 2015) 


\subsubsection{Complement regulation}

Complement regulation is mediated by specific molecules called; complement regulators, which function by preventing the activation or initiation of their degradation (McDonald et al., 2015). These components consist of many soluble and membrane-bound molecules, and they include C1-INH (C1 inhibitor), C4BP, and Factor H (Noris and Remuzzi, 2013). C1-INH inactivates $\mathrm{C} 1 \mathrm{r}$ and $\mathrm{C} 1 \mathrm{~s}$ of $\mathrm{CP}$ and mannan-binding lectin serine protease (MASP-1), MASP2 of the LP from binding, therefore preventing these pathways from being activated. C4BP binds to $\mathrm{C} 4 \mathrm{~b}$ and prevents the formation of $\mathrm{C} 3$ convertase $(\mathrm{C} 4 \mathrm{bC} 2 \mathrm{a})$, while Factor $\mathrm{H}$ degrades the AP C3 convertase (C3bBb) (Regal et al., 2017). Excessive complement activation during pregnancy is controlled by three regulatory proteins on the plasmalemma of trophoblast cells, viz., CD46, CD55, and CD59 (Noris and Remuzzi, 2013). The complement system is also known to initiate cell death in non-infected healthy cells (Ziporen et al., 2009). Complement regulation is known for protection from maternal complement attack by establishing an immune tolerance needed for embryo development and survival (Regal et al., 2017).

Normal placentation is accomplished due to local expression of complement regulators (CD55, CD59, and CD46) and by inhibiting C3 and C5 convertases (Girardi, 2018). Excessive complement activation leads to damage of invading extravillous trophoblasts and placental dysfunction, associated with pregnancy complications, including PE (Lokki et al., 2014).

Activation of the complement system also causes pro-inflammatory and chemotactic anaphylatoxins release, which have the potential to exacerbate inflammation, thrombosis, and vascular leakage. Inadequate regulation of the complement system may also cause tissue damage by pro-inflammatory lesions and an increase in apoptosis (Ito et al., 2015; Rampersad et al., 2008).

\subsubsection{Complement activation}

Complement activation at the maternal-fetal interface, recruits' neutrophils, which increase TNF- $\alpha$ while decreasing VEGF, thereby leading to abnormal placentation (Gelber et al., 2015). Blocking the complement system by the use of inhibitors, viz., serpin, Factor 1, and C4-BP, specifically targets the sites of complement activation, results in neutrophil depletion whilst blocking of TNF- $\alpha$ improves the spiral artery remodelling (Qing et al., 2011). A study conducted by (Lillegard et al., 2013) established a link between hypertension decline in pregnancy and complement activation using a rat model. 
Complement activation results in the release of chemotactic anaphylatoxins and proinflammatory cytokines, which may cause inflammation, thrombosis and vascular leakage (Rampersad et al., 2008). Aberrant complement activation can also result in tissue damage distinguished by inflammatory lesions and increased apoptosis on placental villi (Ito et al., 2015).

\subsubsection{Complement dysregulation}

Evidence demonstrates a dysregulation of the complement component within both the maternal circulation and the placenta (Regal et al., 2017). Lynch et al., (2016) showed dysregulation of the AP activation fragment $\mathrm{Bb}$ in $\mathrm{PE}$, with the highest levels occurring early in pregnancy, highlighting a crucial role for the AP in PE development. In contrast, increased levels of $\mathrm{Bb}$ have been reported in maternal and umbilical venous blood in PE (Hoffman et al., 2014).

Obesity causes complement components to increase and are positively correlated with body mass index (BMI), whilst decreases with weight loss (Moreno-Navarrete and Fernández-Real, 2019). Complement proteins are created primarily by the liver, but they can also be generated by other organs and tissues such as adipose tissues, therefore complement the complement system is activated, and complement components are increased in obesity and increasing BMI (Nilsson et al., 2014).

The risk of PE development rises with an increase in body mass index (BMI) (Roberts et al., 2011). This statement was confirmed by illustrating that bariatric surgery done to reduce obesity, can reduce PE occurrence (Galazis et al., 2014). Maternal obesity, with its circulating factors such as fatty acids, may cause the excess of lipid accumulation in the placenta (Jarvie et al., 2010). This may impede placental development, including angiogenesis and trophoblast, as well as deficient nutrient transfer between mother and fetus (Jarvie et al., 2010). An increase in inflammation caused by pro-inflammatory mediators, such as interleukin (IL6) and tumour necrosis factor (TNF- $\alpha$ ), and oxidative stress, occurs at the maternal-fetal interface and may lead to placental injuries, observed in PE (Saben et al., 2014).

The complement system has been linked to excess adipose tissue and PE development (Nilsson et al., 2014). 


\subsubsection{The complement system in normal and preeclamptic pregnancy- a summary}

During normal pregnancy, immune adaptations are made by the complement system to prevent the rejection of the fetus by the mother, whilst protecting against pathogens (Lannaman et al., 2017). The complement system achieves this by causing a shift in the maternal response from T-helper 1 (Th1) to T-helper 2 (Th2) type immune response (Perez-Sepulveda et al., 2014). Trophoblast cells secrete the complement components, C3, C4 and C1q (Bulla et al., 2012). $\mathrm{C} 1 \mathrm{q}$ is synthesised by decidual endothelial cells, implying a correlation between trophoblast cells and spiral artery endothelial cells (Madhukaran et al., 2016). Additionally, Singh et al., (2011), that C1q plays a role in trophoblast migration and spiral artery remodelling, as C1q deficient mice displayed features of PE such as hypertension and proteinuria.

Complement component $\mathrm{C} 3$ activation was also shown to contribute to normal phagocytic activity in mouse trophoblast cells, and this suggests that $\mathrm{C} 3$ may play a role in trophoblast invasion (Regal et al., 2015). The increase in C5a deposition in macrophages and C5aR appearance in the placental trophoblasts of PE women also demonstrated. C5a inhibited vessel tube formation and migration of trophoblasts, hence leading to inadequate trophoblast invasion (Ma et al., 2018).

Regulatory T cells (Tregs) are a subpopulation of T cells that modulate the immune system, prevent autoimmune diseases and maintain fetal tolerance during pregnancy (Jiang et al., 2014). A decrease in Tregs is observed in PE, and forkhead box P3 (Foxp3+) regulatory T cells develop in the absence of C5aR1 activation (Strainic et al., 2013). The stimulation of C5aR1 induces pro-inflammatory $\mathrm{T}$ cells; therefore, production of C5a during pregnancy may reduce Treg numbers with a concomitant increase in inflammatory $\mathrm{T}$ cells, exacerbating the inflammatory state (Drouin et al., 2006).

Lynch et al., (2008), observed that pregnant women with increased Bb plasma levels during early pregnancy, are at a higher risk of developing PE later on in pregnancy. This suggests that in PE patients, abnormal complement activation may be present during the first trimester (1015 weeks). Most studies of complement activation have been focused after the onset of PE and not during the early stages or first trimester (Denny et al., 2013).

According to He et al., (2020), the abnormal regulation of the complement system by the alternative (increased levels of complement factor B and complement factor $\mathrm{H}$ ) and classical (elevated C1q) pathways, were observed in the first trimester of patients with PE later in pregnancy. It was reported by Denny et al., (2013) and Burwick et al., (2018), that levels of 
C3a, C5a and sC5b-9 are increased in PE patients, suggesting that abnormal complement regulation plays a role in two stages of PE development (Girardi et al., 2006).

In stage 1 (placenta formation), abnormal complement regulation was found to affect the placental formation, which causes the onset of PE later in pregnancy (Girardi et al., 2006; Rampersad et al., 2008). In stage 2 (after the onset of PE), the complement system becomes activated by local placental ischemia and hypoxia, resulting in a cascade of reactions that contribute to the rapid development of PE (Lillegard et al., 2013; Burwick et al., 2018).

\subsubsection{The complement system and angiogenic imbalance}

Several studies have shown an increase in the incidence of PE women, who had increased levels of sFlt-1 and sEng in maternal circulation; therefore, a potential relationship between complement dysregulation and angiogenic imbalance is observed (He et al., 2016). A study by Banadakoppa et al., (2018), reported the in vitro activation of the complement system at sublethal levels on human trophoblast cells caused by the up-regulation of sFlt-1. Additionally, it was also suggested that $\mathrm{C} 3 \mathrm{a}$ increased the levels of mRNA sFlt-1, causing MAC to be released.

\subsubsection{The complement system in the duality of HIV infection and Preeclampsia}

The complement system is vital during viral infection and is the first barrier to manage and maintain the spread of HIV. It also aids in the clearance and neutralisation of HIV (Posch et al., 2011). When HIV-1 enters the host, it activates the complement system via its two glycoproteins, gp41 and gp120, without the need for HIV-specific antibodies and hence it becomes coated with complement fragments (Hladik and McElrath, 2008). Thereafter, adaptive immunity is activated, and specific anti-HIV-1 antibodies and activated $\mathrm{T}$ cells are generated (de Jong and Geijtenbeek, 2010).

In the HIV budding process, HIV acquires regulators of the complement system such as CD55, CD59 and factor $\mathrm{H}$ (figure 1.2). Therefore; the virus is protected from complement-mediated lysis (Roberts et al., 2010). Additionally, it was observed that the complement system or together with dendritic cells (DCs) are involved with priming of antiviral T cell immunity, suggesting the complement system activates lysis and mediates an adaptive immune response (Posch et al., 2011). 


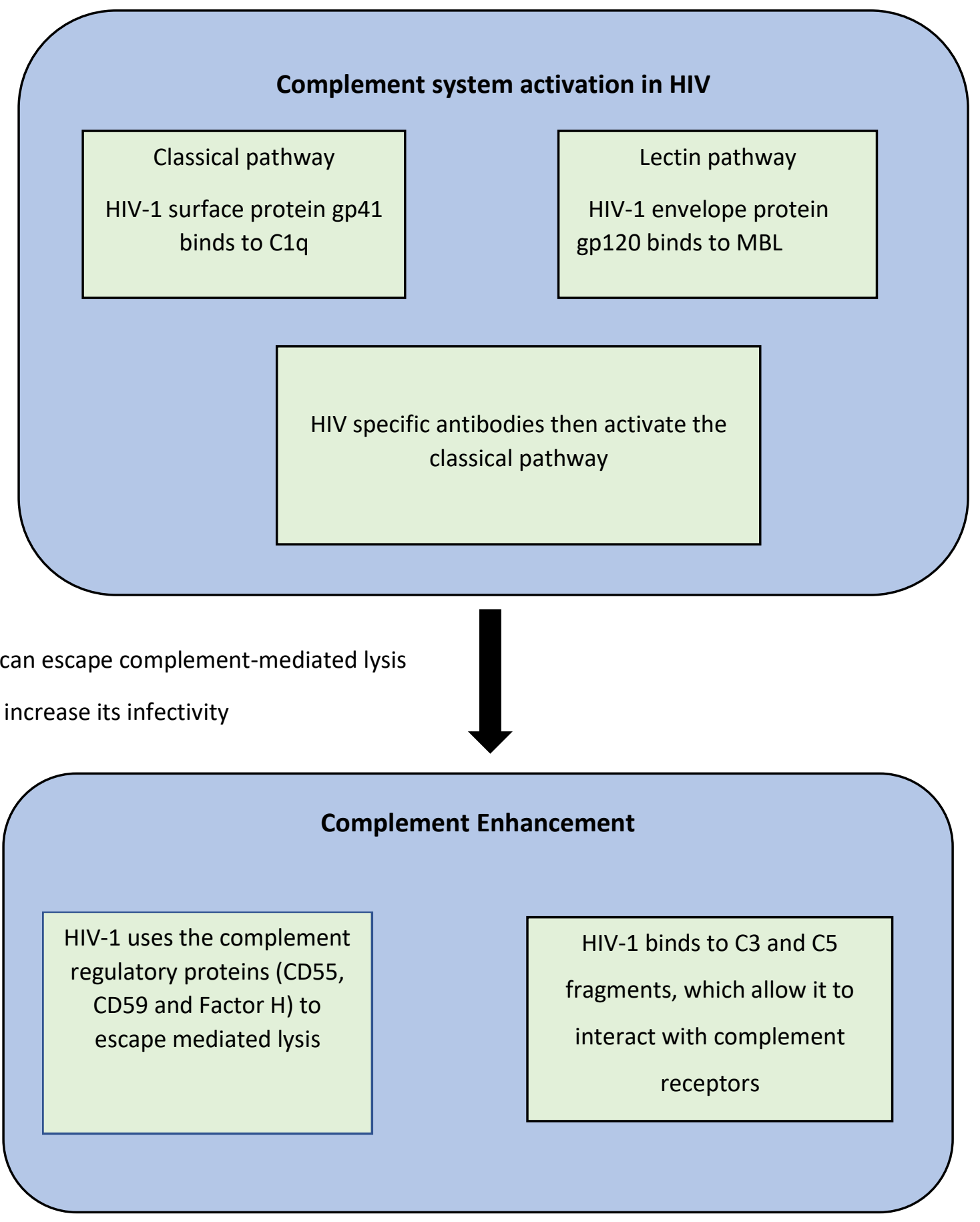

Figure 1.2: Schematic diagram on the role of the complement system during HIV infection. It is activated by HIV1 virus binding to gp41 and gp120. HIV-specific antibodies also contribute to complement activation. HIV-1 uses the regulatory proteins to evade complement-mediated lysis. 
Banki et al., (2010), demonstrated that failure to produce efficient T cell responses without the presence of complement may be attributed to DCs, which engulf C3-coated pathogens to prime CD8+ $\mathrm{T}$ cells, resulting in efficient activation of adaptive immunity. Moreover, in HIVinfected individuals, the NK cell response is impaired, with subsequent defects of cytotoxic activity of NK cells. This impairment begins early after infection and continues during HIV progression (Alter, 2005).

During the early stages of HIV-1 infection, the complement system is activated. The protein gp41 on the surface of HIV-1 binds to C1q and activates the CP (Yu and Qin, 2010), while HIV-1 envelope protein gp120 binds to mannose-binding lectin (Conroy et al., 2017), to neutralise the virus (Eisen and Klein, 2008). MBL then triggers activation of the LP, to increase phagocytic uptake and to inhibit viral entry to susceptible cells (Eisen and Klein, 2008). Despite activation of the complement function during HIV-1 infection. HIV-1 is still able to evade complement-mediated lysis (Yu and Qin, 2010). It accomplishes this by using the complement regulatory proteins (CD 55 and CD59) from the host during its budding process. Factor $\mathrm{H}$ also binds to HIV-1, to provide extra protection from complement attack (Liu et al., 2014).

Dysregulation in complement activation can shift the balance from a normal state to an inflammatory state (Ricklin and Lambris, 2013). C3a and C5a are complement components that are up-regulated in PE (figure 1.3) and are able to induce inflammation, recruit macrophages and dendritic cells (Harman et al., 2016) for HIV-1 infection (Derzsy et al., 2010). An increase of pro-inflammatory cytokines such as IL-6 and TNF- $\alpha$ were occurred in the presence of C5a, to promote HIV-1 infection (Popko et al., 2010). Therefore, the chronic inflammatory state observed in HIV and PE may be aggravated further due to excessive complement activation.

In PE, different complement components are upregulated, suggesting an increase in complement activation, and this can lead to the opsonisation and greater number of HIV virions in HIV-infected women (Alqudah and Yaseen, 2016). The increase in inflammatory cytokines by pro-inflammatory $\mathrm{T}$ cells and a decrease in anti-inflammatory and regulatory cytokines, observed in PE, creates an imbalance leading to chronic immune activation (Rossheim et al., 2016). HIV infection also creates a similar chronic immune activation with the use of HAART (Harman et al., 2016). Excessive or dysregulated complement activation can lead to inflammatory pathology (Rossheim et al., 2016). Excessive or dysregulated complement activation enlists leukocytes (Lynch and Salmon, 2010), which release pro-inflammatory 
cytokines and anti-angiogenic mediators, resulting in an inflammatory state observed in PE (Rossheim et al., 2016).

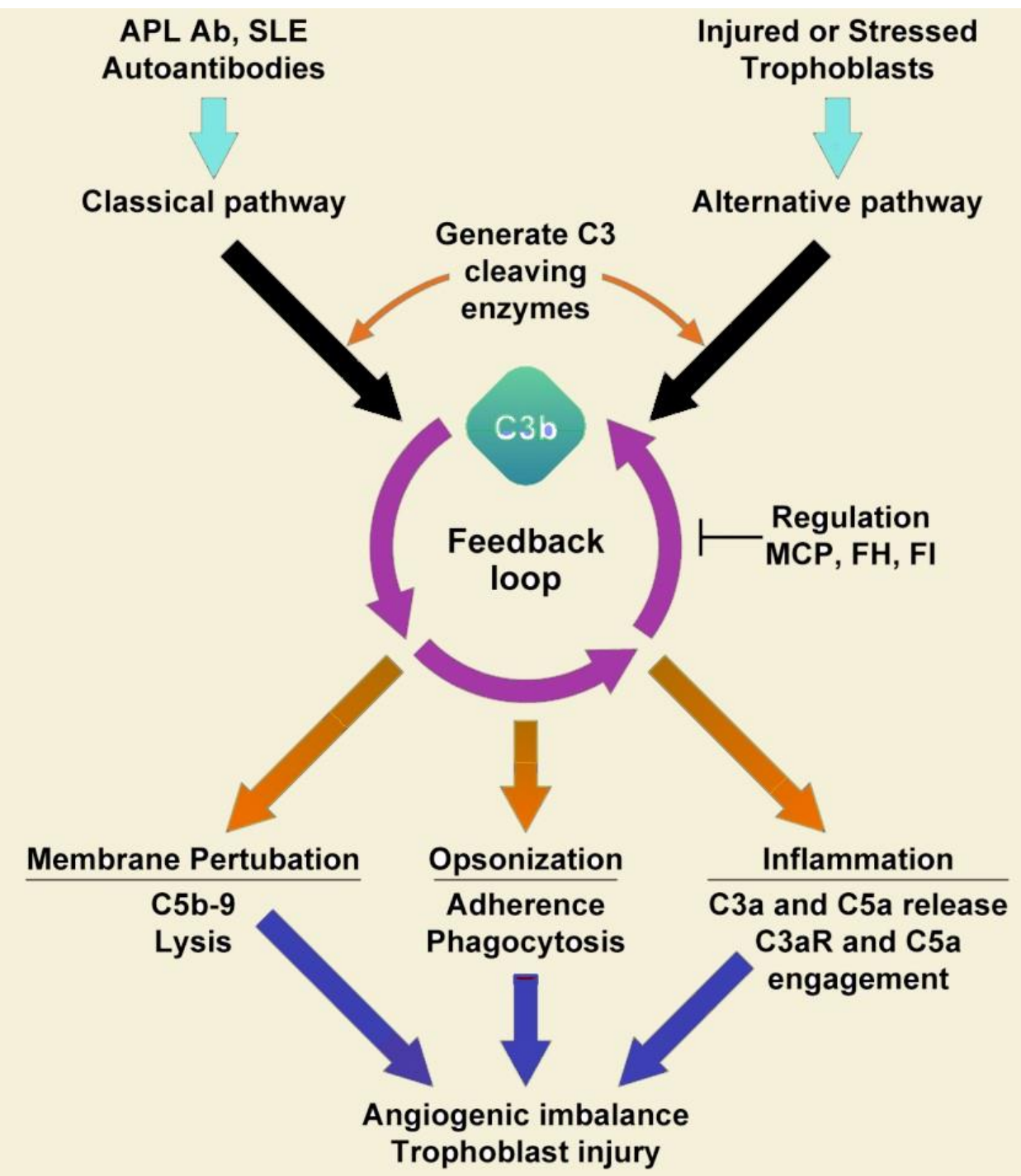

Figure 1.3: Schematic diagram on the role of the complement system in preeclampsia. The pathogenesis of preeclampsia is not fully elucidated; however, there is a potential link between complement dysregulation and angiogenic imbalance. Complement dysregulation leads to an elevated release of complement components, which cause excessive inflammation, and this can lead to angiogenic imbalances and trophoblast injury. Adapted from (Lynch and Salmon, 2010) 


\subsection{Adipsin}

Adipsin, commonly known as Complement Factor D, is a serine protease synthesised and released by adipose tissue. It activates the alternative pathway of the complement system, thus enabling the body's natural defence against infections (Poveda et al., 2016). Adipsin activates complement factor B and causes C3bBb formation (Morgan and Holmes, 2000).

More specifically, complement component (C3) is cleaved by spontaneous hydrolysis of C3 convertase enzyme complex in C3b and C3a (Podos et al., 2018). Lynch et al., (2012) correlated the increase of $\mathrm{C} 3$, together with obesity as a higher risk factor for developing PE. $\mathrm{C} 3 \mathrm{~b}$ forms a complex with factor $\mathrm{B}$. Adipsin cleaves Factor $\mathrm{B}$ into $\mathrm{Ba}$ and $\mathrm{Bb}$ fragments. Factor $\mathrm{Bb}$ binds to $\mathrm{C} 3 \mathrm{~b}$ to form the $\mathrm{C} 3 \mathrm{bBb}$ complex (figure 1.4) (Godahewa et al., 2016). $\mathrm{C} 3 \mathrm{bBb}$ complex, acts as C3 convertase, to amplify the complement cascade (Podos et al., 2018). Additionally, Adipsin plays a part in the formation of the MAC and generation of numerous signalling molecules of the complement system (Gómez-Banoy et al., 2019).

Adipsin is insulin-sensitive and was found to increase insulin levels in response to glucose and bring about homeostasis in adipose tissue (Lo et al., 2014). Several studies have revealed that Adipsin plays an important role in sepsis (Dahlke et al., 2011) and ischemic reperfusion (Stahl et al., 2003). These conditions cause excessive inflammation and releasing pro-inflammatory cytokines, similarly observed in PE (Ouchi et al., 2011). This will therefore cause the complement system to be activated, to regulate the excess inflammation (Derzsy et al., 2010), thus Adipsin levels will be increased. 


\section{Adipsin (Factor D)}

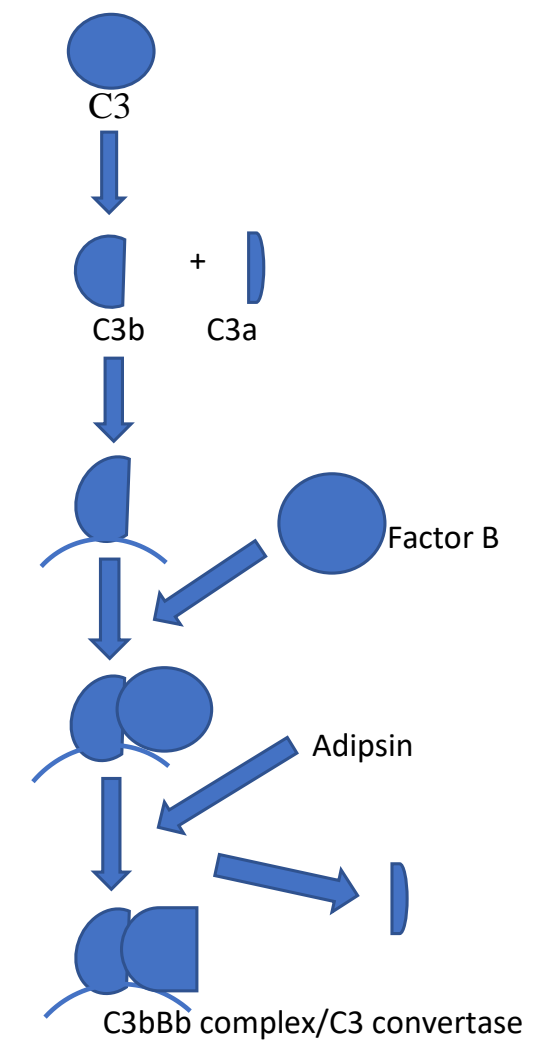

Figure 1.4: Illustration of the action of Adipsin in the complement system. C3 is spontaneously cleaved to form $\mathrm{C} 3 \mathrm{a}$ and $\mathrm{C} 3 \mathrm{~b}$. Adipsin cleaves Factor $\mathrm{B}$ to $\mathrm{Ba}$ and $\mathrm{Bb}$. Factor $\mathrm{Bb}$ binds to $\mathrm{C} 3 \mathrm{~b}$ and forms the $\mathrm{C} 3 \mathrm{bBb}$ complex, which acts as $\mathrm{C} 3$ convertase, to amplify the complement cascade. Adapted from RuizOjeda., (2018).

Plasma Adipsin levels were elevated in obese individuals, positively correlated to BMI and insulin resistance (Maslowska et al., 1999). An increase in BMI leads to a greater risk of developing PE (Roberts et al., 2011) and obesity. Additionally, obesity results in an increase in complement components (Moreno-Navarrete and Fernandez-Keal, 2019), Adipsin being one such. In a study by Sivakumar et al., (2013), elevated Adipsin levels were observed in obese pregnant women. Furthermore, the study showed Adipsin positive areas in particular cells (Hofbauer cells), spread broadly in the placenta, specifically the perivascular area. 
In the study conducted by Takeshita et al., (2010), changes in Adipsin concentrations in placentas of mouse abortuses was determined. Adipsin immunoreactivity was recorded to be elevated at the junctional and labyrinth zones of the abortion placenta sites. This evidence suggests that Adipsin may play a role in the up-regulation of complement activity in the placenta, and this up-regulation is implicated in complement dysregulation in PE (Kusakabe et al., 2008).

Since there is no cure for PE, early diagnosis and treatment are crucial for sustaining pregnancy. A simple, rapid, and inexpensive assay is needed. This test should also be specific and sensitive for PE diagnosis. Urinalysis is one such test that meets these requirements, and Wang et al., (2014) identified urinary adipsin protein as a potential biomarker for PE diagnosis. Urinary Adipsin was found to be best correlated with the 24-hour urine protein. Urinary Adipsin concentrations were elevated in preeclamptic women compared to non-preeclamptic and healthy non-pregnant women. This evidence suggests that urinary Adipsin could be used as a rapid diagnostic test and biomarker for PE. Additionally, it was reported that in some pregnant women who had high Adipsin concentrations, the babies were delivered prematurely and newborn babies tended to be lower in body weight, factors associated with PE (Wang et al., 2014).

\subsection{Complement component C9}

Complement component 9 (C9) is a membrane protein used in the hosts' defence against pathogens. It is also involved in the pathogenesis of a number of liver disorders, liver injury and repair (Joller et al., 2011; Wagner and Frank, 2010). C9 functions as the pore-forming component of the membrane attack complex (MAC), (figure 1.5). The MAC comprises of C5, C6, C7, C8, and C9 components and targets bacteria and envelops parasites and viruses (Dudkina et al., 2016). C9 is also able to form poly-c9 structures, which closely resemble the MAC pore. During MAC formation, numerous copies of C9 are recruited in sequence to membrane-associated C5b8, to form a pore and thus to cause lysis (Spicer et al., 2018).

The MAC also causes numerous physiologic changes, including apoptosis and the release of pro-inflammatory cytokines (Vlaicu et al., 2013). The release of pro-inflammatory cytokines (TNF- $\alpha$, IL-2), causes excessive inflammation resulting in greater complement activation 
(Regal et al., 2017). Brewster et al., (2008) showed increased levels of the C5b-9 MAC in PE, indicating excessive complement activation and hyper inflammation, like that in PE.

According to Sun et al, (2017), the complement signalling pathways were observed to be downregulated in HIV co-infected patients. This is most likely due to the dampening effects of HIV on the immune system (Kalumba et al., 2013).

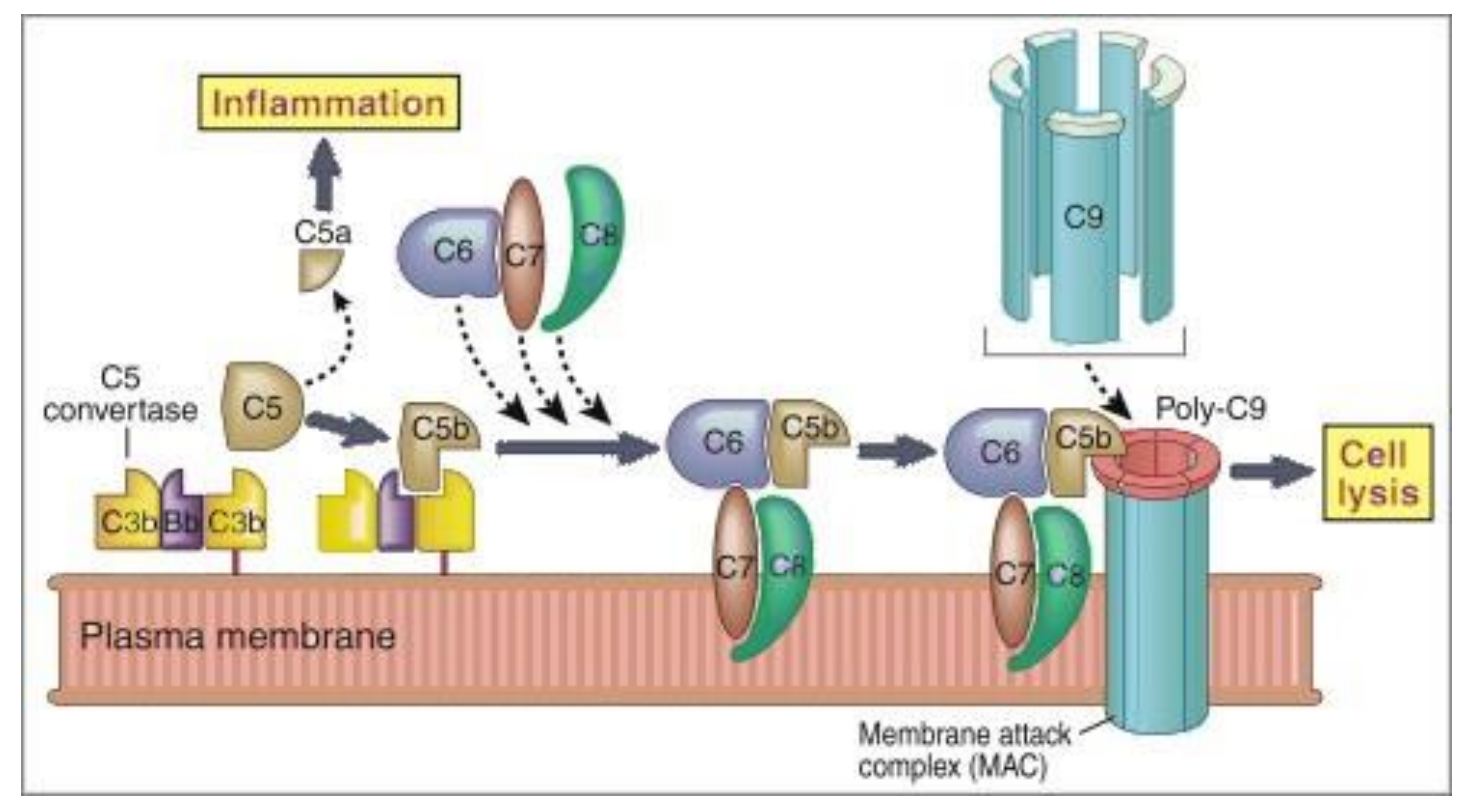

Figure 1.5: Schematic diagram on the function of complement component C9. C9 recruits complement components C5-8 to form a pore in the membrane attack complex, which causes lysis to occur. Adapted from (Andrade et al., 2017).

The synthesis and release of excessive amounts of biologically active products during the complement cascade activation due to PE may cause tissue damage via the MAC (Girardi et al., 2006). The fetal-maternal interface is potentially a target of the complement system, where its physiological function may cause damage (Le Bouteiller et al., 2003). The vascular changes to the spiral arteries in PE, favours complement activation, with the possibility of placental damage (Bulla et al., 2012). Several studies demonstrated the late complement components (C5, C6 and C9) are found in the placenta (Girardi et al., 2006). The study by Rampersad et al., (2008), also reported that C5b-9 MAC on trophoblasts was related to fibrin deposits in the sites of villous injury in PE. Complement C9 was found on the trophoblast's membrane (Romero et al., 2007); this suggests that C9 and the complement system may be activated 
during the vascular remodelling process in PE. There is still insufficient evidence on C9 and its function to HIV-associated PE.

Therefore, this study examines the concentration of Adipsin and C9 in the duality of HIV infection and PE stratified by pregnancy type and HIV status.

\subsection{Hypothesis}

Adipsin and C9 would be altered by HIV infection and preeclampsia

\subsubsection{Aims of study}

To determine the immunoexpression of Adipsin and C9 in the duality of HIV and Preeclampsia

\subsubsection{Specific objectives}

2. This study will compare the concentration of Adipsin and C9 in normotensive pregnancies compared to preeclamptic pregnancies irrespective of HIV status, using the Bioplex immunoassay procedure.

3. This study will compare the concentrations of Adipsin and C9 by HIV status regardless of pregnancy type, using the Bioplex immunoassay procedure.

4. This study will compare the concentration of Adipsin and C9 across the study population.

5. This study will compare patient demographics with Adipsin and C9 concentration across the study population 
CHAPTER 2 


\section{Citation:}

Mikyle David, Jagidesa Moodley and Thajasvarie Naicker. The function of adipsin and C9 protein in the complement system in HIV-associated preeclampsia. 


\section{Human Immunology}

THE FUNCTION OF ADIPSIN AND C9 PROTEIN IN THE COMPLEMENT SYSTEM IN HIV-ASSOCIATED PREECLAMPSIA --Manuscript Draft--

\begin{tabular}{|c|c|}
\hline \multicolumn{2}{|l|}{ Manuscript Number: } \\
\hline Article Type: & Research Paper \\
\hline Keywords: & Preeclampsia; HIV; Adipsin; C9 \\
\hline Corresponding Author: & $\begin{array}{l}\text { Mikyle David, Master of Medical Sciences } \\
\text { University of KwaZulu-Natal Nelson R Mandela School of Medicine: University of } \\
\text { KwaZulu-Natal College of Health Sciences } \\
\text { Durban, KwaZulu-Natal SOUTH AFRICA }\end{array}$ \\
\hline First Author: & Mikyle David, Master of Medical Sciences \\
\hline \multirow[t]{3}{*}{ Order of Authors: } & Mikyle David, Master of Medical Sciences \\
\hline & Jagidesa Moodley \\
\hline & Thajasvarie Naicker \\
\hline Abstract: & $\begin{array}{l}\text { Objective } \\
\text { In preeclampsia, there are excessive complement components expressed due to } \\
\text { increased complement activation; therefore, this study investigated the concentration } \\
\text { of adipsin and C9 in HIV-associated preeclampsia. } \\
\text { Method } \\
\text { The study population ( } n=76 \text { ) was stratified by pregnancy type (normotensive pregnant } \\
\text { and preeclampsia) and by HIV status. Serum was assayed for the concentration of } \\
\text { adipsin and C9 using a Bioplex immunoassay procedure. } \\
\text { Results } \\
\text { Maternal weight did not differ ( } p=0.1196 \text { ) across the study groups. The } \\
\text { concentration of adipsin was statistically different between the PE vs normotensive } \\
\text { pregnant groups, irrespective of HIV status ( } p=0.0439 \text { ). There was no significant } \\
\text { difference in adipsin concentration between HIV-negative vs HIV-positive groups, } \\
\text { irrespective of pregnancy type ( } p=0.6290 \text { ). Additionally, there was a significant } \\
\text { difference in adipsin concentration between HIV negative normotensive vs HIV } \\
\text { negative preeclampsia ( } p<0.05 \text { ), as well as a difference between HIV negative } \\
\text { preeclampsia vs HIV positive preeclampsia ( } p<0.05 \text { ). C9 protein expression was } \\
\text { not statistically different between the normotensive and PE groups, regardless of HIV } \\
\text { status ( } p=0.5365 \text { ). No statistical significance in C9 expression was found between } \\
\text { HIV positive vs HIV negative groups, regardless of pregnancy type ( } p=0.3166 \text { ). } \\
\text { Similarly, no statistical significance was noted across all study groups ( } p=0.0774 \text { ). } \\
\text { Conclusion } \\
\text { This study demonstrates that there is a strong correlation between the up-regulation of } \\
\text { adipsin and PE and that adipsin is a promising biomarker to use as a diagnostic tool for } \\
\text { PE. }\end{array}$ \\
\hline \multirow[t]{3}{*}{ Suggested Reviewers: } & $\begin{array}{l}\text { Olive Pearl Khaliq, Doctor of philosophy } \\
\text { lecturer, University of Kwazulu-Natal } \\
\text { KhaliqO@ukzn.ac.za }\end{array}$ \\
\hline & $\begin{array}{l}\text { Nalini Govender, PHD } \\
\text { senior lecturer, DUT: Durban University of Technology } \\
\text { Nalinip@dut.ac.za }\end{array}$ \\
\hline & $\begin{array}{l}\text { Wendy Phoswa, P.H.D } \\
\text { Lecturer, University of KwaZulu-Natal Nelson R Mandela School of Medicine: }\end{array}$ \\
\hline
\end{tabular}




\section{THE FUNCTION OF ADIPSIN AND C9 PROTEIN IN THE COMPLEMENT SYSTEM IN HIV-ASSOCIATED PREECLAMPSIA}

Mikyle David $^{\mathrm{a}^{*},{ }^{\mathrm{a}} J a g i d e s a}$ Moodley and Thajasvarie Naicker ${ }^{\mathrm{b}}$

${ }^{\mathrm{b} O p t i c s}$ and Imaging Centre, Dorris Duke Medical Research Institute, Nelson R. Mandela School of Medicine, College of Health Sciences, University of KwaZulu-Natal, Durban, KwaZulu-Natal, South Africa

a'Women's Health and HIV Research Group, Department of Obstetrics and Gynecology, Nelson R. Mandela School of Medicine, University of KwaZulu-Natal, Durban, South Africa

\section{*Corresponding author:}

Mikyle David

Optics \& Imaging Centre

Doris Duke Medical Research Institute

Nelson R. Mandela School of Medicine

University of KwaZulu-Natal,

Durban, South Africa

Email address: mikyledavid101@gmail.com; naickera@ukzn.ac.za 


\section{Abstract:}

Objective: In preeclampsia, there are excessive complement components expressed due to increased complement activation; therefore, this study investigated the concentration of adipsin and C9 in HIV-associated preeclampsia.

Method: The study population $(n=76)$ was stratified by pregnancy type (normotensive pregnant and preeclampsia) and by HIV status. Serum was assayed for the concentration of adipsin and C9 using a Bioplex immunoassay procedure.

Results: Maternal weight did not differ $(p=0.1196)$ across the study groups. The concentration of adipsin was statistically different between the PE vs normotensive pregnant groups, irrespective of HIV status $(p=0.0439)$. There was no significant difference in adipsin concentration between HIV-negative vs HIV-positive groups, irrespective of pregnancy type $(p=0.6290)$. Additionally, there was a significant difference in adipsin concentration between HIV negative normotensive $v s$ HIV negative preeclampsia $(p<0.05)$, as well as a difference between HIV negative preeclampsia $v s$ HIV positive preeclampsia $(p<0.05)$. C9 protein expression was not statistically different between the normotensive and PE groups, regardless of HIV status ( $p=0.5365$ ). No statistical significance in C9 expression was found between HIV positive $v s$ HIV negative groups, regardless of pregnancy type $(p=0.3166)$. Similarly, no statistical significance was noted across all study groups $(p=0.0774)$.

Conclusion: This study demonstrates that there is a strong correlation between the upregulation of adipsin and $\mathrm{PE}$ and that adipsin is a promising biomarker to use as a diagnostic tool for PE.

Keywords: Preeclampsia, HIV, Adipsin, C9

Running title:

Total word count: 4039

Word count, excluding abstract and references: 2659

Number of figures: 2

Number of tables: 1 


\section{Introduction}

Hypertensive disorders of pregnancy (HDP) and non-pregnancy related infections (HIV infection, TB) are the most common causes of maternal mortality in South Africa (Moodley et $a l ., 2019)$. Hypertensive disorders in pregnancy account for approximately $18 \%$ of all maternal deaths in South Africa (Moodley et al., 2018). In high-income countries, the prevalence of HDP is $5-10 \%$, the frequency being higher in low-middle-income (LMIC) countries (Naicker et al., 2019). Preeclampsia (PE) is a complex pregnancy-specific disorder, accounting for 500000 fetal and neonatal deaths and approximately 70000 maternal deaths worldwide (Gathiram and Moodley, 2016). It is diagnosed by new-onset hypertension (BP $\geq 140 \mathrm{mmHg}$ or $\geq 90 \mathrm{mmHg}$ diastolic) after 20 weeks of gestation, with/without proteinuria ( $\geq 300 \mathrm{mg}$ ) (Brown et al., 2018). Preeclampsia is accompanied by multiple organ dysfunction and severe maternal complications that may include-the liver, kidney, etc. and hemolysis, elevated liver enzymes, and low platelet count referred to as the "HELLP" syndrome (Phipps et al., 2016) (Brown et al., 2018). In South Africa, the prevalence of PE is $12 \%$ (Onyangunga et al., 2019). The World Health Organization (WHO) reports a significant disparity in the prevalence of PE in highincome countries compared to LMICs [1.6\% versus 1.8-16.7\% respectively] (WHO., 2019).

Preeclampsia is a heterogeneous disease and may be divided into two main subtypes, viz., early and late-onset PE (Staff et al., 2013). The clinical signs for early-onset PE (EOPE) occur before 33 gestational weeks, whilst those of late-onset PE (LOPE) appears after 34 weeks of gestation. Late-onset PE constitutes the majority (>80\%) of cases (Gathiram and Moodley, 2016). The early-onset type is associated with abnormal placentation and correlates with high maternal and fetal morbidity and mortality rates (Von Dadelszen et al., 2003). The pathogenesis of PE is not fully understood as yet. However, it is generally accepted that inadequate myometrial spiral artery remodelling due to deficient migration of extravillous trophoblast (EVT) cells is involved in the pathophysiology of PE. (McNally et al., 2017). During normal pregnancy, the trophoblast begins migration from the tips of anchoring villi through the decidua and the myometrium accompanied by spiral artery remodelling (Maître, 2017). In PE, there is shallow trophoblast invasion of the maternal myometrial spiral arteries, which leads to a reduction in the diameters of spiral arterioles resulting in decreased blood flow and subsequent placental hypoxia and fetal growth restriction (Li et al., 2015).

The human immunodeficiency virus (HIV) is a retrovirus that invades a host, impairing cellular immunity and increasing one's susceptibility to opportunistic pathogens (Maartens et al., 
2014). Human immunodeficiency virus infection is a global pandemic, with 38 million people living with and 1.7 million people newly infected with HIV at the end of 2019 (UNAIDS, 2020). South Africa has a population of 7.97 million people (13.5\%) infected with HIV (SA STATS, 2019 ), of which 4.7 million are women in their reproductive age (UNAIDS, 2020). Around $30 \%$ of South African pregnant women are infected with HIV, with the province of KwaZulu-Natal having a prevalence of approximately 37\% (Kalumba et al., 2013). The association between HIV infection and PE originates from opposing immune responses, as PE induces an exaggerated immune response (Than et al., 2008), whilst HIV dampens the immune response (Kalumba et al., 2013).

The complement system forms part of the innate immune system and consists of numerous plasma and cell membrane proteins (Merle et al., 2015). The complement system is initiated by three main pathways viz., the classical pathway (CP), the lectin pathway (LP), and the alternative pathway (AP), each culminating in one common pathway (Noris and Remuzzi, 2013). The function of the complement system is the opsonization of target surfaces, induction of pro-inflammatory responses, and the lysis of cells and pathogens. It is also vital in the defence of the host by clearing apoptotic cells, injured tissue, and immune complexes, thus contributing to physiological homeostasis (Lokki et al., 2014).

During normal pregnancy, for the mother to tolerate the semi-allogenic fetus, the immune system mediates a T helper 2 (Th2) response modulated by cytokines such as IL-10 (Saito et al., 2007). Simultaneously, a T helper 1 (Th1) pro-inflammatory response is mediated by cytokines such as TNF- $\alpha$ and IL-2 (Otun et al., 2011). Th1/Th2 response is critical for trophoblast invasion, parturition and protection against pathogens (Osman et al., 2003) and the balance between Th1 and 2 response is essential to ensure a successful pregnancy. However, during pregnancy, complications such as PE, a shift from Th2 to Th1 occurs (Perez-Sepulveda et al., 2014). This is due to cell-mediated immune responses that contribute to an overall increase in the maternal systemic inflammatory response (Saito and Sakai, 2003).

Adipsin, commonly known as Complement Factor D, is a serine protease that activates the AP. Adipsin is synthesized and released by adipose tissue. Adipsin levels are higher in PE compared to normotensive pregnant women (Poveda et al., 2016). This upregulation of adipsin levels elicits complement activation, leading to an exaggerated inflammatory response (Regal et al., 2017). 
Similar to adipsin, complement component 9 (C9) is a membrane protein used as a defence against pathogens. Complement component 9 functions as the pore-forming component of the membrane attack complex (MAC). During MAC formation, numerous copies of C9 are recruited in sequence to membrane-associated $\mathrm{C} 5 \mathrm{~b} 8$, to form a pore and thus to cause lysis (Spicer et al., 2018). Moreover, the complement signalling pathways are downregulated by HIV infection (Guha and Ayyavoo, 2013). This is most likely due to the HIV attacking the CD4+ T cells and thus dampening the immune system (Balasubramaniam et al., 2019).

Notwithstanding this observation, there is a lack of research with regards to the function of adipsin and C9 in the duality of HIV infection and PE.

Therefore, this study examines the expression of adipsin and C9 in the duality of HIV infection and PE stratified by pregnancy type and HIV status, using the Bioplex multiplex immunoassay procedure. 


\section{Materials and methods:}

This study was approved by the Biomedical Research Ethics Administration, University of KwaZulu-Natal, Durban, South Africa. Ethics No: BCA 338/17.

This was a prospective study that utilized retrospectively collected samples stored at $-80^{\circ} \mathrm{C}$. The study population $(n=76)$ was used to determine a moderate effect size of 0.66 between the groups. The study population was recruited from a large regional hospital in Durban, South Africa. Two groups of normotensive pregnant and preeclamptic women were stratified by their HIV status into, HIV negative normotensive pregnant women, and HIV positive normotensive pregnant women, HIV negative PE and HIV positive PE women. To detect a large effect size of 0.95 , a sample size of 19 was required in each group.

Bioplex immunoassay:

A MILLIPLEX MAP ${ }^{\mathrm{TM}}$ Human Complement Panel one was performed according to manufacturer's instructions (Millipore by Sigma-Aldrich, catalogue no: HCMP1MAG-19K). The standards were prepared in a 1:100 dilution series. In a 96 well plate, adipsin and C9 capture antibody-coupled magnetic beads were added to each well and washed twice. Standards, samples and blanks were then added into their designated wells and left to incubate before washing three times. Thereafter, a biotinylated detection antibody was pipetted into each well and allowed to incubate. The plate was then washed three times before adding streptavidin-phycoerythrin throughout the wells. Finally, the plate was washed for a further three times, before resuspending each well with assay buffer. The plate was then ready to be placed into the Bio-Plex ${ }^{\mathrm{TM}}$ system for reading. The Bio-Plex1MAGPIXTM Multiplex Reader (Bio-Rad Laboratories Inc., USA) was utilized to read the experiment plate. Bio-Plex Manager ${ }^{\mathrm{TM}}$ software version 4.1 was used to obtain the data from the multiplex analysis.

Statistical analysis

Data was analysed using GraphPad Prism 5.00 for Windows (GraphPad Software, San Diego California USA). Results are represented as the median and interquartile range (IQR). A T-test for normality revealed parametrically distributed data. A Mann-Whitney $U$ test was used to determine statistical significance according to pregnancy type (normotensive $v s$ PE) and HIV (negative $v s$ positive). Statistical significance was determined across all groups, using a oneway ANOVA test, a Kruskal-Wallis test in combination with Dunn's multiple comparison post hoc test was used. Statistical significance was reported as $p<0.05$. 


\section{Results}

$\underline{\text { Patient demographics and clinical characteristics }}$

The patient demographics and their clinical characteristics are shown in table 1. No statistical significance was reported in weight $(p=0.1196)$ across the study groups. Statistical significance was reported for gestational age, systolic blood pressure (BP) and diastolic BP ( $p$ $<0.0001)$, as well as parity and maternal age $(p<0.05)$ across study groups.

Table 1: Demographic data and clinical profile of participants across all study groups.

\begin{tabular}{|l|l|l|l|l|l|}
\hline & $\begin{array}{l}\text { Normotensive } \\
\text { HIV Negative } \\
\mathrm{n}=19\end{array}$ & $\begin{array}{l}\text { Normotensive } \\
\text { HIV Positive } \\
\mathrm{n}=19\end{array}$ & $\begin{array}{l}\text { Preeclamptic } \\
\text { HIV Negative } \\
\mathrm{n}=19\end{array}$ & $\begin{array}{l}\text { Preeclamptic } \\
\text { HIV Positive } \\
\mathrm{n}=19\end{array}$ & $p$-value \\
\hline $\begin{array}{l}\text { Maternal Body Weight } \\
(\mathrm{kg})\end{array}$ & $74(22)$ & $81(28)$ & $90(46)$ & $83(36)$ & 0.1196 \\
\hline Gestational Age (weeks) & $37(9)$ & $25(14)$ & $24(10)$ & $23(10)$ & $0.0008^{* * *}$ \\
\hline Parity & $1(1)$ & $2(1)$ & $1(2)$ & $2(1)$ & $0.0085^{*}$ \\
\hline $\begin{array}{l}\text { Systolic blood pressure } \\
\text { (mmHg) }\end{array}$ & $109(20)$ & $112(16)$ & $146(14)$ & $147(20)$ & $<0.0001 * * *$ \\
\hline $\begin{array}{l}\text { Diastolic blood pressure } \\
\text { (mmHg) }\end{array}$ & $65(13)$ & $72(14)$ & $92(9)$ & $97(13)$ & $<0.0001 * * *$ \\
\hline Maternal Age (years) & $25(4)$ & $31(11)$ & $29(16)$ & $34(14.5)$ & $0.0304 *$ \\
\hline
\end{tabular}

Patient demographics amongst study groups $(n=76)$. Results are represented as the median (IQR), * $p<0.05 * * * p<0.001$

\section{$\underline{\text { Serum concentrations of adipsin }}$}

Pregnancy type: The concentration of Adipsin was statistically different between the PE group (median=10239 pg/mL, IQR=6632 pg/mL) and normotensive group (median=8335 pg/mL, $\mathrm{IQR}=5485 \mathrm{pg} / \mathrm{mL}$ ), irrespective of HIV status (Mann-Whitney $\mathrm{U}=652, p=0.0439$; figure 1A)

HIV status: There was no significant difference in adipsin concentrations between HIVnegative $($ median=5498 pg/mL, IQR=8532 pg/mL) vs HIV-positive groups (median=8345 $\mathrm{pg} / \mathrm{mL}, \mathrm{IQR}=7453 \mathrm{pg} / \mathrm{mL}$ ), irrespective of pregnancy type (Mann-Whitney $\mathrm{U}=675, p=0.6290$; figure 1B).

Across all groups: There was a significant difference in adipsin concentration between HIV negative normotensive (median $=3607 \mathrm{pg} / \mathrm{mL}, \quad \mathrm{IQR}=5947 \mathrm{pg} / \mathrm{mL}$ ) vs HIV negative 
preeclampsia $($ median $=11972 \mathrm{pg} / \mathrm{mL}, \mathrm{IQR}=3240 \mathrm{pg} / \mathrm{mL} ; p<0.05)$, as well as a difference between HIV negative preeclampsia (median=11972 pg/mL, IQR=3240 pg/mL) vs HIV positive preeclampsia (median $=4849 \mathrm{pg} / \mathrm{mL}, \mathrm{IQR}=9618 \mathrm{pg} / \mathrm{mL} ; p<0.05$ ). No differences were found amongst the other groups of pregnant women (Kruskal-Wallis $\mathrm{H}=11.68, p=0.0086$; figure 1C).

$1 \mathrm{~A}$

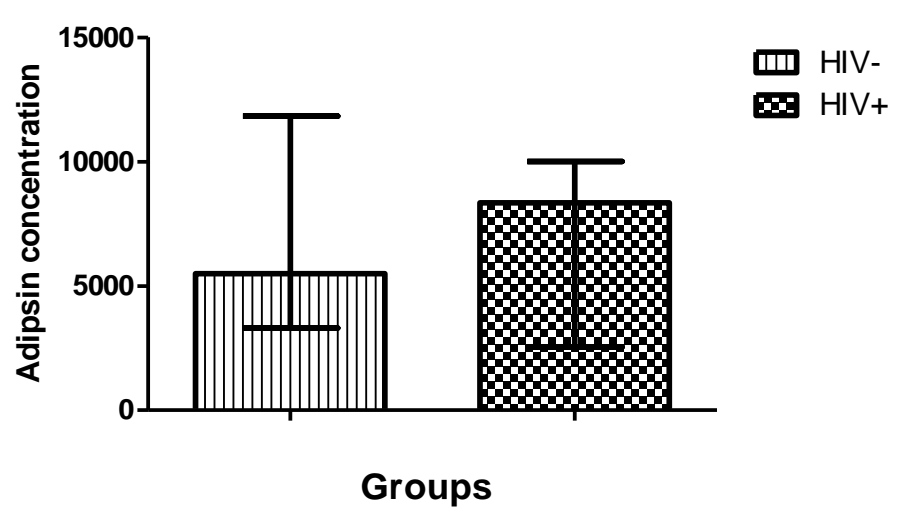

1B

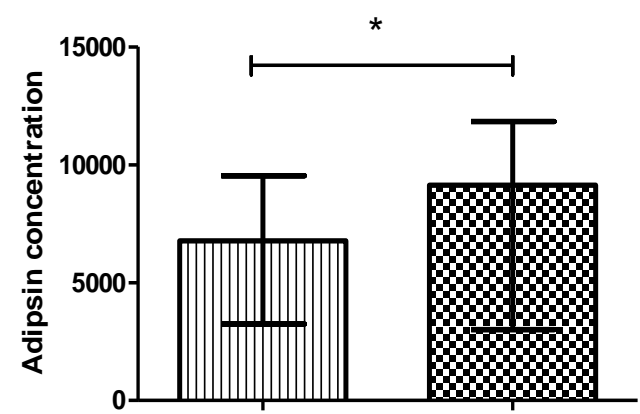

Normotensive

ax Preeclampsia

Groups 


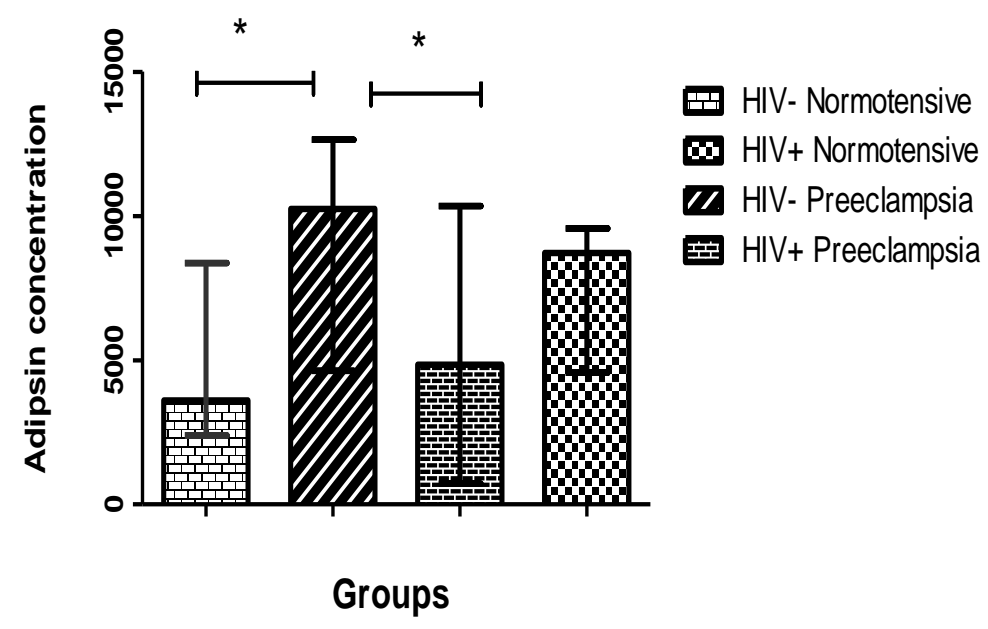

Figure 1: The Histogram illustrating serum concentration of adipsin (A) Preeclamptic vs Normotensive groups; (B) HIV positive vs HIV negative groups; (C) Across all groups. Data is represented by median and interquartile range. $*$ p value $<0.05$.

Serum concentrations of C9

Pregnancy type: C9 protein expression was not statistically different between the normotensive (median=4039 pg/mL, IQR=3683 pg/mL), and PE groups (median=4876 pg/mL, IQR=4169 $\mathrm{pg} / \mathrm{mL}$ ), regardless of HIV status (Mann-Whitney $\mathrm{U}=13.50, p=0.5365$; figure $2 \mathrm{~A}$ ).

HIV status: No statistical significance in C9 expression was found between HIV positive groups $($ median $=3180 \mathrm{pg} / \mathrm{mL}, \mathrm{IQR}=4830 \mathrm{pg} / \mathrm{mL}$ ) vs HIV negative groups (median=4610 $\mathrm{pg} / \mathrm{mL}, \mathrm{IQR}=2791 \mathrm{pg} / \mathrm{mL}$ ), regardless of pregnancy type (Mann-Whitney $\mathrm{U}=13.50, p=0.3166$; figure $2 \mathrm{~B}$ ).

Across all groups: Similarly, no statistical significance was noted across all study groups (Kruskal-Wallis $\mathrm{H}=9.514, p=0.0774$; figure 2C). 
$2 A$

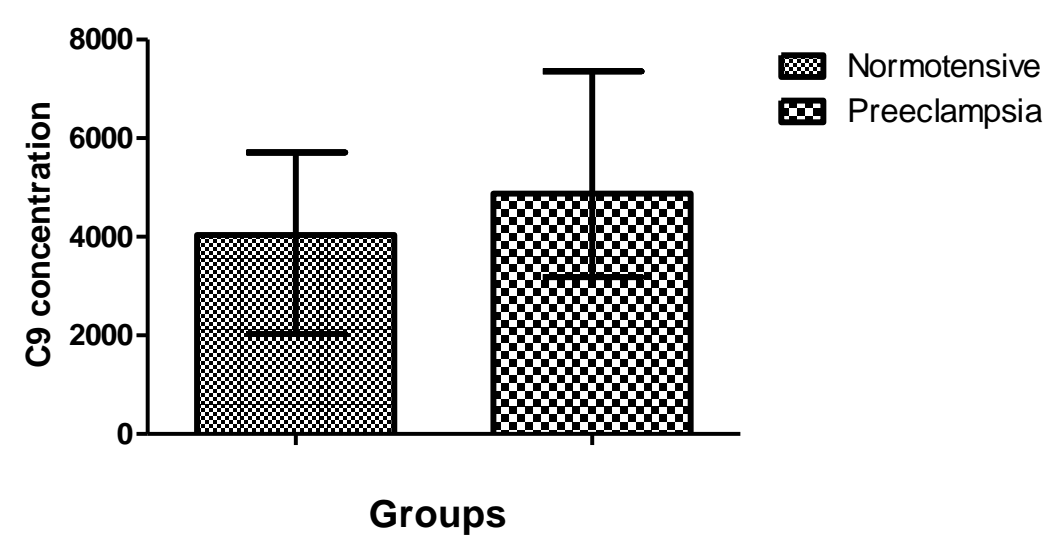

2B

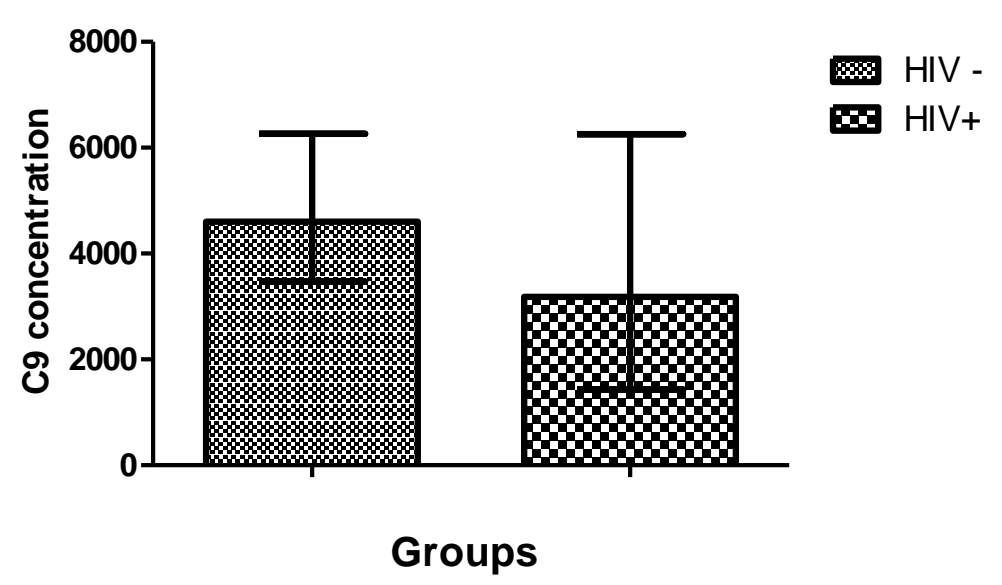

2C

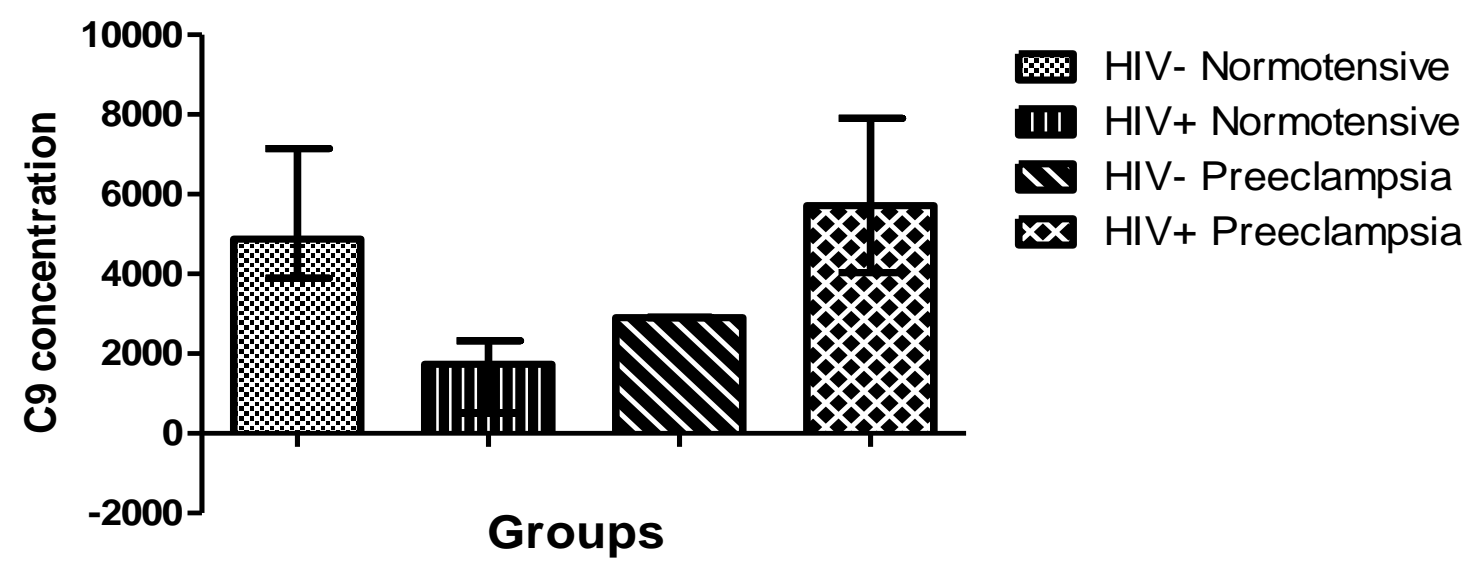

Figure 2: Histogram illustrating the serum concentration of C9; (A) Preeclamptic vs Normotensive groups; (B) HIV positive vs HIV negative groups; (C) Across all groups. Data is represented as median and interquartile range. 


\section{Discussion}

The main finding of this novel study was the significant up-regulation of adipsin in the preeclamptic compared to the normotensive pregnant group, regardless of HIV status [figure $1 \mathrm{~A} ; p=0.0439$ ]. Poveda et al. (2016) reported similar findings in PE compared to normotensive pregnancy, albeit late in pregnancy (Poveda et al., 2016). Notably, our study reflects adipsin concentration at term. Moreover, increased serum adipsin levels have been previously reported to correlate with an elevation of urinary adipsin in PE patients (Wang et al., 2014; Wang et al., 2016). Preeclampsia is characterized by glomerular endotheliosis (Gangaram et al., 2005). The latter two studies suggest that urinary adipsin may be used as a predictor test value for diagnosing PE development.

Adipsin is a serine protease synthesized and released by adipose tissue; in our study, maternal body weight was similar between normotensive and preeclamptic groups. As mentioned earlier, adipsin forms C3 convertase, thereby increasing complement activation (Choy and Spiegelman, 1996). Off note, adipsin generates an acylation-stimulating protein (C3adesArg/ASP) (Morgan and Holmes, 2000) to stimulate triglyceride synthesis (Cianflone et al., 2003). During pregnancy, triglyceride levels are a risk factor for the development of PE and preterm birth (Ghio et al., 2011). Acylation-stimulating protein signalling also activates the $\mathrm{P} 13 \mathrm{~K}$, protease kinase $\mathrm{C}$, Akt and MAPK/ERK1/2 pathways, which are vital for trophoblast cell migration

This increase in adipsin levels may cause excessive complement activation, which may lead to pro-inflammatory and chemotactic anaphylatoxins being released, which have the potential to cause excessive inflammation in PE (Regal et al., 2017). Several studies have correlated an increase in adipsin concentrations with body mass index (BMI) in PE compared to normotensive pregnant women; unfortunately, BMI was not available for our study population (Wang et al., 2014; Takeshita et al., 2010). An increase in BMI is associated with obesity and insulin resistance (Saad et al., 2016). It is noteworthy that metabolic conditions such as obesity and diabetes results in chronic inflammation, a hallmark feature in PE (Rossheim et al., 2016). It is, therefore, plausible that the elevation in adipsin may be due to metabolic changes that occur in pregnancy and in PE development (Perez-Sepulveda et al., 2014). In a recent study by He et al. (2020), a dysregulation of the alternative pathway in PE during the first trimester was observed, but this returned to normal pregnancy levels in the second trimester; adipsin in our study reflected term pregnancy. 
Our study also found that serum adipsin concentrations were not influenced by HIV status, regardless of pregnancy type. The similarity in adipsin between the groups may be attributed to antiretroviral drug usage, a standard of care practice for HIV infection in South Africa. The effects of HAART are those of re-establishing the immune system and therefore, immune response (Landi et al., 2014). It is plausible that a compromised immune system due to HIV infection triggers a compensatory response of adipsin, to increase complement activation. This change in adipsin concentrations is most likely due to the immunological changes of the complement system, brought about by HIV infection (Yu, 2010), in tandem with HAART administration. Also, protease inhibitors impede triglyceride accumulation via modulation of ASP production (Soliman et al., 2009).

This novel study also demonstrates no significant difference in serum C9 concentration between normotensive and PE, irrespective of HIV status. In contrast, several other studies report higher C9 concentrations in PE compared to healthy pregnancies (Burwick et al., 2020; Derzsy et al., 2010). It is plausible that these results are due to excessive complement activation, as a result of the hyper-inflammatory state caused by $\mathrm{PE} . \mathrm{C} 3\left(\mathrm{H}_{2} \mathrm{O}\right)$ is cleaved by $\mathrm{C} 9$ to generate $\mathrm{C} 3$ convertase. This cleavage is slower without properdin, a positive regulator of AP convertase (Hourcade, 2006)

This study reports similar C9 concentrations based on HIV status. C9 is involved in the formation of the membrane attack complex, a part of our innate immune response that leads to the killing of foreign pathogens. The similar levels may be attributed to antiretroviral therapy in our study (Dudkina et al., 2016). The administration of HAART plays a conflicting role in these results, as it is known to reconstitute the immune system (Landi et al., 2014) whilst other studies indicate the opposite (Umar et al., 2020). Also, HIV escapes complement attack by exploiting complement regulators such as CD55, and CD59 (Liu et al., 2014). Also, cancer cells reduce MAC concentration, is influenced by CD59 up-regulation, where it removes plasma membrane MAC via vesiculation (Shi et al., 2009). Moreover, patients with a deficiency of C9 protein are unable to form the MAC (Frank, 2000). Due to the lack of information on $\mathrm{C} 9$ in the duality of $\mathrm{HIV}$-associated PE, further research is required.

One of the limitations of this study was the small sample size. Additionally, all the HIVpositive women were on HAART treatment, which may have confounded differences in analyte expression. The heterogeneity of the study population, which was not stratified into early and late-onset PE, may be seen as a limitation. 


\section{Conclusion}

This study demonstrates a significant up-regulation of adipsin in PE compared to normotensive pregnancies, this finding correlates with the exaggerated inflammatory milieu of PE. Complement C9 protein was similar between pregnancy types. This similarity may emanate from properdin dysregulation or a genetic polymorphism. The concentration of adipsin and C9 proteins were not affected by HIV status due to the immune reconstitution effect of antiretroviral therapy. Furthermore, the up-regulation of adipsin in placental sites and urinary levels of PE in previous studies, in tandem with our findings, indicate the possibility of adipsin as a predictor value for PE development.

\section{Declaration of interest}

There are no conflicts of interest

\section{Acknowledgements}

The study was funded by the College of Health Science, UKZN.

\section{References}

BALASUBRAMANIAM, M., PANDHARE, J. \& DASH, C. (2019). Immune Control of HIV. Journal of life sciences (Westlake Village, Calif.), 1, 4-37.

BROWN, M. A., MAGEE, L. A., KENNY, L. C., KARUMANCHI, S. A., MCCARTHY, F. P., SAITO, S., HALl, D. R., WARREN, C. E., ADOYI, G., ISHAKU, S. \& INTERNATIONAL SOCIETY FOR THE STUDY OF HYPERTENSION IN, P. (2018). Hypertensive Disorders of Pregnancy: ISSHP Classification, Diagnosis, and Management Recommendations for International Practice. Hypertension, 72, 24-43.

CHOY, L. N. \& SPIEGELMAN, B. M. (1996). Regulation of alternative pathway activation and C3a production by adipose cells. Obesity Research, 4, 521-522.

CIANFLONE, K., XIA, Z. \& CHEN, L. Y. (2003). Critical review of acylation-stimulating protein physiology in humans and rodents. Biochimica et Biophysica Acta (BBA)-Biomembranes, 1609, 127-143.

FRANK, M. M. (2000). Complement deficiencies. Pediatric Clinics of North America, 47, 1339-1354. 
GANGARAM, R., OJWANG, P., MOODLEY, J. \& MAHARAJ, D. (2005). The accuracy of urine dipsticks as a screening test for proteinuria in hypertensive disorders of pregnancy. Hypertension in Pregnancy, 24, 117-123.

GATHIRAM, P. \& MOODLEY, J. (2016). Pre-eclampsia: its pathogenesis and pathophysiolgy. Cardiovascular Journal of Africa, 27, 71.

GHIO, A., BertolotTo, A., RESI, V., VOLPE, L. \& DI CIANNI, G. (2011). Triglyceride metabolism in pregnancy. Advances In Clinical Chemistry, 55, 134.

GUHA, D. \& AYYAVOO, V. (2013). Innate immune evasion strategies by human immunodeficiency virus type 1. ISRN AIDS, 2013, 954806-954806.

HOURCADE, D. E. (2006). The role of properdin in the assembly of the alternative pathway C3 convertases of complement. Journal of Biological Chemistry, 281, 2128-2132.

KALUMBA, V., MOODLEY, J. \& NAIDOO, T. (2013). Is the prevalence of pre-eclampsia affected by HIV/AIDS? A retrospective case-control study. Cardiovascular Journal of Africa, 24, 24.

LI, H., OHTA, H., TAHARA, Y., NAKAMURA, S., TAGUCHI, K., NAKAGAWA, M., OISHI, Y., GOTO, Y.-I., WADA, K. \& KAGA, M. (2015). Artificial oxygen carriers rescue placental hypoxia and improve fetal development in the rat pre-eclampsia model. Scientific Reports, 5, 15271.

LOKKI, A. I., HEIKKINEN-ELORANTA, J., JARVA, H., SAISTO, T., LOKKI, M.-L., LAIVUORI, H. \& MERI, S. (2014). Complement activation and regulation in preeclamptic placenta. Frontiers in Immunology, 5, 312.

MAARTENS, G., CELUM, C. \& LEWIN, S. R. (2014). HIV infection: epidemiology, pathogenesis, treatment, and prevention. The Lancet, 384, 258-271.

MAÎTRE, J. L. (2017). Mechanics of blastocyst morphogenesis. Biology of the Cell, 109, 323-338.

MCNALLY, R., ALQUDAH, A., OBRADOVIC, D. \& MCCLEMENTS, L. (2017). Elucidating the pathogenesis of pre-eclampsia using in vitro models of spiral uterine artery remodelling. Current Hypertension Reports, 19, 93. 
MERLE, N. S., CHURCH, S. E., FREMEAUX-BACCHI, V. \& ROUMENINA, L. T. (2015). Complement system part I-molecular mechanisms of activation and regulation. Frontiers in Immunology, 6, 262.

MOODLEY, J., FAWCUS, S. \& PATTINSON, R. (2018). Improvements in maternal mortality in South Africa. South African Medical Journal, 108, 4-8.

MOODLEY, J., SOMA-PILlAY, P., BUCHMANN, E. \& PATTINSON, R. (2019). Hypertensive disorders in pregnancy: 2019 National guideline. South African Medical Journal, 109.

MORGAN, B. P. \& HOLMES, C. H. (2000). Immunology of reproduction: protecting the placenta. Current Biology, 10, R381-R383.

NAICKER, T., PHOSWA, W. N., ONYANGUNGA, O. A., GATHIRAM, P. \& MOODLEY, J. (2019). Angiogenesis, Lymphangiogenesis, and the Immune Response in South African Preeclamptic Women Receiving HAART. International Journal Of Molecular Sciences, 20, 3728.

NORIS, M. \& REMUZZI, G. (2013). Overview of complement activation and regulation. Seminars in Nephrology, 479-492.

ONYANGUNGA, O., NAICKER, T. \& MOODLEY, J. (2019). Maternal and perinatal outcomes after caesarean delivery in early and late onset preeclampsia with HIV positive and HIV negative South African Women. Nigerian Journal Of Clinical Practice, 22, 591.

OSMAN, I., YOUNG, A., LEDINGHAM, M. A., THOMSON, A. J., JORDAN, F., GREER, I. A. \& NORMAN, J. E. (2003). Leukocyte density and pro-inflammatory cytokine expression in human fetal membranes, decidua, cervix and myometrium before and during labour at term. MHR: Basic Science Of Reproductive Medicine, 9, 41-45.

OTUN, H. A., LASH, G. E., INNES, B. A., BULMER, J. N., NARUSE, K., HANNON, T., SEARLE, R. F. \& ROBSON, S. C. (2011). Effect of tumour necrosis factor- $\alpha$ in combination with interferon- $\gamma$ on first trimester extravillous trophoblast invasion. Journal Of Reproductive Immunology, 88, 1-11.

PEREZ-SEPULVEDA, A., TORRES, M. J., KHOURY, M. \& ILLANES, S. E. (2014). Innate immune system and preeclampsia. Frontiers in Immunology, 5, 244. 
PHIPPS, E., PRASANNA, D., BRIMA, W. \& JIM, B. (2016). Preeclampsia: updates in pathogenesis, definitions, and guidelines. Clinical Journal of the American Society of Nephrology, 11, 11021113.

POVEDA, N. E., GARCÉS, M. F., RUIZ-LINARES, C. E., VARÓN, D., VALDERRAMA, S., SANCHEZ, E., CASTIBLANCO-CORTES, A., AGUDELO-ZAPATA, Y., SANDOVALALZATE, H. F., LEAL, L. G., ÁNGEL-MÜLLER, E., RUÍZ-PARRA, A. I., GONZÁLEZCLAVIJO, A. M., DIÉGUEZ, C., NOGUEIRAS, R. \& CAMINOS, J. E. (2016). Serum Adipsin Levels throughout Normal Pregnancy and Preeclampsia. Scientific Reports, 6, 20073-20073.

REGAL, J. F., BURWICK, R. M. \& FLEMING, S. D. (2017). The complement system and preeclampsia. Current Hypertension Reports, 19, 87.

ROSSHEIM AEB, C. T., HAIR PS, SHAN T, ET AL (2016). effects of well controlled HIV infection on complement activation and function. Journal of Acquired Immune Deficiency Syndrome, 73, 20-26.

SAAD, M., SANTOS, A. \& PRADA, P. (2016). Linking gut microbiota and inflammation to obesity and insulin resistance. Physiology, 31(4): 283-293.

SAITO, S. \& SAKAI, M. (2003). Th1/Th2 balance in preeclampsia. Journal Of Reproductive Immunology, 59, 161-173.

SAITO, S., SHIOZAKI, A., SASAKI, Y., NAKASHIMA, A., SHIMA, T. \& ITO, M. (2007). Regulatory T cells and regulatory natural killer (NK) cells play important roles in feto-maternal tolerance. Seminars In Immunopathology, 115-122.

SPICER, B. A., LAW, R. H., CARADOC-DAVIES, T. T., EKKEL, S. M., BAYLY-JONES, C., PANG, S.-S., CONROY, P. J., RAMM, G., RADJAINIA, M. \& VENUGOPAL, H. (2018). The first transmembrane region of complement component-9 acts as a brake on its selfassembly. Nature Communications, 9, 1-7.

STAFF, A. C., BENTON, S. J., VON DADELSZEN, P., ROBERTS, J. M., TAYLOR, R. N., POWERS, R. W., CHARNOCK-JONES, D. S. \& REDMAN, C. W. (2013). Redefining preeclampsia using placenta-derived biomarkers. Hypertension, 61, 932-942.

SA STATS. 2019 Mid year population estimates 2019. Statistics South Africa. 
THAN, N. G., EREZ, O., WILDMAN, D. E., TARCA, A. L., EDWIN, S. S., ABBAS, A., HOTRA, J., KUSANOVIC, J. P., GOTSCH, F. \& HASSAN, S. S. (2008). Severe preeclampsia is characterized by increased placental expression of galectin-1. The Journal of Maternal-Fetal \& Neonatal Medicine, 21, 429-442.

UMAR, A., ORIPELAYE, M., OLANREWAJU, F., ONAYEMI, O., OLASODE, O. \& ONINLA, O. (2020). Determinants of discordant immune response in a cohort of human immunodeficiency virus-infected patients initiating antiretroviral therapy. Sahel Medical Journal, 23, 22-28.

UNAIDS 2020. UNAIDS Global HIV \& AIDS statistics—2020 fact sheet.

VON DADELSZEN, P., MAGEE, L. A. \& ROBERTS, J. M. (2003). Subclassification of preeclampsia. Hypertension in Pregnancy, 22, 143-148.

WANG, T., ZHOU, R., GAO, L., WANG, Y., LIU, X. \& ZHANG, L. (2016). Clinical assessment of the specificity of an adipsin rapid test for the diagnosis of preeclampsia. Hypertension in Pregnancy, 35, 420-425.

WANG, T., ZHOU, R., GAO, L., WANG, Y., SONG, C., GONG, Y., JIA, J., XIONG, W., DAI, L. \& ZHANG, L. (2014). Elevation of urinary adipsin in preeclampsia: correlation with urine protein concentration and the potential use for a rapid diagnostic test. Hypertension, 64, 846-851.

YU Q, Y. R., QIN X (2010). The good and evil of complement activation in HIV-1 infection. Cellular Molecular Immunology, 7, 334-340. 
CHAPTER 3 


\subsection{Synthesis}

\subsubsection{Problem Identification}

HIV infection remains one of the world's leading health concerns, with 38 million people living with and 1.7 million people newly infected with HIV at the end of 2019. Women and girls account for approximately $48 \%$ of all new HIV infections in 2019, and in Sub-Saharan Africa, women and girls account for 59\% of all new infections. The prevalence of HIV infection in South Africa is $13.5 \%$ (SA STATS, 2019), of which 4.7 million are women in their reproductive age (UNAIDS, 2019). Approximately 30\% of South African women who are pregnant are infected with HIV (Kalumba et al., 2013), with the province of KwaZulu-Natal having the highest prevalence. South Africa has the largest antiretroviral therapy (ART) rollout in the world (Nlooto and Naidoo, 2016). In contrast to HIV infection, ART reconstitutes the immune system (Kalumba et al., 2013).

In South Africa, HIV infection (31\%) and hypertensive disorders of pregnancy (17\%) account for the majority of maternal deaths (Moodley et al., 2018; Saving Mothers Report, 2017). Preeclampsia is a multisystemic disorder of pregnancy, accounting for $83 \%$ of HDP (Gathiram and Moodley, 2016). In normotensive pregnancies, adaptations of the innate and adaptive immune system are activated to ensure the survival of the fetus, whilst also protecting the mother (Pierik et al., 2019). During PE, however, there is deficient maternal tolerance or an altered immune response due to the increased release of monocytes and neutrophils, which results in excessive inflammation (Perez-Sepulveda et al., 2014).

The complement system is an integral part of the innate immune system and is comprised of various plasma proteins and cell membranes (Merle et al., 2015). Additionally, it is important in defence of the host by clearing injured tissue, immune complexes and acts as a mediator of the adaptive immune response (Lokki et al., 2014). During viral infection, the complement system is essential, as it is the first defence barrier to manage and maintain the spread of HIV. It also assists in the clearance and neutralisation of HIV (Posch et al., 2011). Adipsin is a serine protease, that activates the alternative pathway of the complement system, therefore activating the body's natural defence against pathogens (Poveda et al., 2016). Complement C9 is a membrane protein, and the last of the complement components (Wagner and Frank, 2010). It is used in the hosts' defence against pathogens. C9 recruits other complement components (C5C8) to form the membrane attack complex (MAC) (Dudkina et al., 2016), which causes several immunological changes including Apoptosis and the release of pro-inflammatory cytokines 
(Vlaicu et al., 2013). These changes result in elevated complement activation, therefore excessive inflammation, as that in PE (Brewster et al., 2008). This study investigates the dysregulation of complement components, adipsin and C9 in HIV associated normotensive pregnant vs preeclamptic women, using a multiplex immunoassay technique.

\subsubsection{Adipsin concentration in HIV associated pregnancy}

The main finding of our study was that the concentration of adipsin was statistically different between the PE $v s$ normotensive pregnant groups, irrespective of HIV status $(p=0.0439)$. Poveda et al. (2016) reported similar findings in PE compared to normotensive pregnancy, albeit late in pregnancy (Poveda et al., 2016). Notably, our study reflects adipsin concentration at term. Moreover, increased serum adipsin levels have been previously reported to correlate with an elevation of urinary adipsin in PE patients (Wang et al., 2014) (Wang et al., 2016).

Adipsin is a protease produced by adipose tissue and activates the alternative pathway. In our study, the maternal weight did not differ $(p=0.1196)$ across the study groups. This similarity may be attributed to the immune-reconstitutive effect of ART's (Maharaj et al., 2017). Nonetheless, it is plausible that the upregulation of adipsin in PE in our study may due to the exaggerated inflammatory state of PE. Also, adipsin produces an acylation-stimulating protein (C3adesArg/ASP) (Morgan and Holmes, 2000) that synthesis triglycerides (Cianflone et al., 2003). Acylation-stimulating protein signals via the P13K, protease kinase C, Akt and MAPK/ERK1/2 pathways that mediate trophoblast cell invasiveness. Notably, triglyceride elevation is a risk factor for complications of pregnancy and intra-uterine growth retardation and small for gestational age infants. (Ghio et al., 2011).

In our study, there was no significant difference in adipsin concentration between HIV-negative $v s$ HIV-positive groups, irrespective of pregnancy type $(p=0.6290)$. This similarity may emanate from antiretroviral drug usage, a standard of care practice for HIV infection in South Africa. Notably, HAART re-constitutes the immune system and therefore, immune response (Landi, 2014). HIV infection triggers complement activation of adipsin (Yu, 2010), in conjunction with HAART administration. Furthermore, protease inhibitors regulate ASP secretion, thereby preventing triglyceride build-up (Soliman et al., 2009). 


\subsubsection{C9 concentration in HIV associated pregnancy}

In our study, C9 protein concentration was not statistically different between the normotensive and PE groups, regardless of HIV status ( $p=0.5365)$. In contrast, several other studies report higher C9 concentrations in PE compared to healthy pregnancies (Burwick et al., 2020; Derzsy et al., 2010). Notably, these results are due to excessive complement activation, emanating from the hyper-inflammatory environment of PE. The cleavage of $\mathrm{C} 3\left(\mathrm{H}_{2} \mathrm{O}\right)$ by $\mathrm{C} 9$ to produce C3 convertase. Properdin, a positive regulator of AP convertase, reduces this reaction (Hourcade, 2006). Complement C9 was found on the trophoblast membrane of PE patients, suggesting that the complement system and $\mathrm{C} 9$ may play a role during the vascular remodelling in PE (Romero et al., 2007). Additionally, urinary Adipsin levels were elevated in PE women, suggesting that Adipsin has the potential to be a biomarker for PE (Wang et al., 2016).

In our study, no statistical significance in C9 concentration was noted between HIV positive $v s$ HIV negative groups, regardless of pregnancy type $(p=0.3166)$. C9 functions to create the membrane attack complex, which plays a role in the opsonization of foreign pathogens (HIV). The similar levels may be attributed to antiretroviral therapy in our study (Dudkina et al., 2016). Also, HIV escapes complement attack by exploiting complement regulators such as CD55, and CD59 (Liu F et al., 2014). A deficiency of the complement protein C9 results in the patient's inability to form MAC (Frank, 2000).

Similarly, no statistical significance of C9 was noted across all study groups $(p=0.0774)$ and may be attributed to ART, properdin dysregulation and genetic polymorphisms of complement components.

\subsubsection{Limitations of the study}

The limitations of this study include small sample size, the heterogeneity of the study population and the fact that all HIV-positive women received ART, which may have confounded analyte expression. Lastly, the PE group was not stratified by gestational age into early and late-onset subtypes.

\subsubsection{Conclusion}

This novel study demonstrates a significant up-regulation of adipsin in PE compared to normotensive pregnancies, regardless of HIV status. This finding correlates with the hyperinflammatory state of PE. Additionally, C9 was similar between normotensive pregnant and PE, irrespective of HIV status. This similarity is possibly due to properdin maladaptation, 
or from a genetic variation. We also demonstrate that adipsin and C9 levels were not affected by HIV status due to the immune reconstitution effect of antiretroviral therapy. Furthermore, the up-regulation of adipsin in placental sites and urinary levels of PE in previous studies, in tandem with our findings, indicate the possibility that adipsin has a predictor value for PE development.

CHAPTER 4 


\section{REFERENCES}

ALAIN, F. T. \& RAOUF, A. K. (2010). Circulating and Vascular Bioactive Factors During Hypertension in Pregnancy. Current Bioactive Compounds, 6, 60-75.

ALTER, G., TEIGEN, N., DAVIS, B. T., ADDO, M. M., SUSCOVICH, T. J., WARING, M. T., STREECK, H., JOHNSTON, M. N., STALLER, K. D. \& ZAMAN, M. T. (2005). Sequential deregulation of NK cell subset distribution and function starting in acute HIV-1 infection. Blood, 106, 3366-3369.

ALQUDAH MAY, Y. M., YASEEN MMS (2016). HIV-1 strategies to overcome the immune system by evading and invading innate immune system. HIV AIDS Reviews, 15, 1-12.

ALRAHMANI L, W. M. (2018). the complement alternative pathway and preeclampsia. Current Hypertension Reports, 20, 40.

ANDRADE, F., LIDANI, K., CATARINO, S. \& MESSIAS-REASON, I. (2017). Serine Proteases in the Lectin Pathway of the Complement System. Proteases in Physiology and Pathology, 397-420. https://doi.org/10.1007/978-981-10-2513-6_18.

AOUACHE, R., BIQUARD, L., VAIMAN, D. \& MIRALLES, F. (2018). Oxidative stress in preeclampsia and placental diseases. International Journal of Molecular Sciences, 19, 1496.

BALASUBRAMANIAM, M., PANDHARE, J. \& DASH, C. (2019). Immune Control of HIV. Journal of Life Sciences, 1, 4-37.

BANKI, Z., POSCH, W., EJAZ, A., OBERHAUSER, V., WILLEY, S., GASSNER, C., STOIBER, H., DITTMER, U., DIERICH, M. P. \& HASENKRUG, K. J. (2010). Complement as an endogenous adjuvant for dendritic cell-mediated induction of retrovirus-specific CTLs. PLoS Pathogens, 6, 4.

BANADAKOPPA, M., BALAKRISHNAN, M. \& YALLAMPALLI, C. (2018). Upregulation and release of soluble fms-like tyrosine kinase receptor 1 mediated by complement activation in human syncytiotrophoblast cells. American Journal of Reproductive Immunology, 80, e13033. 
BOWEN, J., CHAMLEY, L., MITCHELL, M. \& KEELAN, J. (2002). Cytokines of the placenta and extra-placental membranes: biosynthesis, secretion and roles in establishment of pregnancy in women. Placenta, 23, 239-256.

BREWSTER, J. A., ORSI, N. M., GOPICHANDRAN, N., MCSHANE, P., EKBOTE, U. V. \& WALKER, J. J. (2008). Gestational effects on host inflammatory response in normal and pre-eclamptic pregnancies. European Journal of Obstetrics \& Gynecology and Reproductive Biology, 140, 21-26.

BROWN, M. A., MAGEE, L. A., KENNY, L. C., KARUMANCHI, S. A., MCCARTHY, F. P., SAITO, S., HALL, D. R., WARREN, C. E., ADOYI, G., ISHAKU, S. \& INTERNATIONAL SOCIETY FOR THE STUDY OF HYPERTENSION IN, P. (2018). Hypertensive Disorders of Pregnancy: ISSHP Classification, Diagnosis, and Management Recommendations for International Practice. Hypertension, 72, 24-43.

BULLA, R., BOSSI, F. \& TEDESCO, F. (2012). The complement system at the embryo implantation site: friend or foe? Frontiers in Immunology, 3, 55.

BURWICK, R. M., VELASQUEZ, J.A., VALENCIA, C.M., GUTIERREZ-MARIN, J., EDNAESTRADA, F., \& SILVA, J. L., ET AL., (2018). Terminal complement activation in Preeclampsia. Obstetics and Gynecology Forum, 132, 1477-1485.

CHAI, H., YANG, H., YAN, S., LI, M., LIN, P. H., LUMSDEN, A. B., YAO, Q. \& CHEN, C. (2005). Effects of $5 \mathrm{HIV}$ protease inhibitors on vasomotor function and superoxide anion production in porcine coronary arteries. JAIDS Journal of Acquired Immune Deficiency Syndromes, 40, 12 19.

CHEN, L., LIU, B., ZHAO, H., STONE, P., CHEN, Q. \& CHAMLEY, L. (2010). IL-6, TNF $\alpha$ and TGF $\beta$ promote nonapoptotic trophoblast deportation and subsequently causes endothelial cell activation. Placenta, 31, 75-80.

CHEN, J. Y., RIBAUDO, H.J., SOUDA, S., PAREKH, N., OGWU, A., LOCKMAN, S., POWIS, K., DRYDEN-PETERSON, S., CREEL, T., JIMBO, W. AMD MADIDIMALO, T., (2012). HAART and adverse birth outcomes among HIV-infected women in Botswana. The Journal Of Infectious Diseases, 206, 1695-1705. 
CHOY, L. N. \& SPIEGELMAN, B. M. (1996). Regulation of alternative pathway activation and C3a production by adipose cells. Obesity Research, 4, 521-522.

CIANFLONE, K., XIA, Z. \& CHEN, L. Y. (2003). Critical review of acylation-stimulating protein physiology in humans and rodents. Biochimica et Biophysica Acta (BBA)-Biomembranes, 1609, 127-143.

CONROY, A. L., MCDONALD, C.R., GAMBLE, J.L., OLWOCH, P., NATUREEBA, P., COHAN, D., KAMYA, M.R., HAVLIR, D.V., DORSEY, G. AND KAIN, K.C., (2017). Altered angiogenesis as a common mechanism underlyingpreterm birth, small for gestational age and stillbirth in women living with HIV. American Journal of Obstetrics and Gynecology, 217, 684-e681.

DAHLKE, K., WRANN, C. D., SOMMERFELD, O., SOßDORF, M., RECKNAGEL, P., SACHSE, S., WINTER, S. W., KLOS, A., STAHL, G. L. \& MA, Y. X. (2011). Distinct different contributions of the alternative and classical complement activation pathway for the innate host response during sepsis. The Journal of Immunology, 186, 3066-3075.

DE JONG, M. A. \& GEIJTENBEEK, T. B. (2010). Langerhans cells in innate defense against pathogens. Trends in Immunology, 31, 452-459.

DE VRIESE, A. S., SETHI, S., VAN PRAET, J., NATH, K. A. \& FERVENZA, F. C. (2015). Kidney Disease Caused by Dysregulation of the Complement Alternative Pathway: An Etiologic Approach. Journal of the American Society of Nephrology, 26, 2917-2929.

DENNY KJ, W. T., TAYLOR SM, CALLAWAY LK (2013). complement in pregnancy: a delicate balance. American Journal of Reproductive Immunology, 69, 3-11.

DERZSY, Z., PROHÁSZKA, Z., RIGÓ JR, J., FÜST, G. \& MOLVAREC, A. (2010). Activation of the complement system in normal pregnancy and preeclampsia. Molecular Immunology, 47, 15001506.

DROUIN, S. M., SINHA, M., SFYROERA, G., LAMBRIS, J.D. AND WETSEL, R.A., (2006). A protective role for the fifth complement component (c5) in allergic airway disease. American Journal Of Respiratory And Critical Care Medicine, 173, 852-857. 
DUDKINA, N. V., SPICER, B. A., REBOUL, C. F., CONROY, P. J., LUKOYANOVA, N., ELMLUND, H., LAW, R. H., EKKEL, S. M., KONDOS, S. C., GOODE, R. J., RAMM, G., WHISSTOCK, J. C., SAIBIL, H. R. \& DUNSTONE, M. A. (2016). Structure of the poly-C9 component of the complement membrane attack complex. Nature Communication, 7, 10588.

EISEN S, D. A., KLEIN NJ (2008). Mannose binding lectin in HIV infection. Future Virology, 3, 225233.

FOURIE, C., VAN ROOYEN, J., SCHUTTE, A., PIETERS, M., CONRADIE, K. \& HOEKSTRA, T. (2011). Is HIV-1 infection associated with endothelial dysfunction in a population of African ancestry in South Africa? Cardiovascular Journal of Africa, 22, 134.

FRANK, M. M. (2000). Complement deficiencies. Pediatric Clinics of North America, 47, 1339-1354.

GALAZIS, N., DOCHEVA, N., SIMILLIS, C. \& NICOLAIDES, K. H. (2014). Maternal and neonatal outcomes in women undergoing bariatric surgery: a systematic review and meta-analysis. European Journal of Obstetrics and Gynecology and Reproductive Biology, 181, 45-53.

GANGARAM, R., OJWANG, P., MOODLEY, J. \& MAHARAJ, D. (2005). The accuracy of urine dipsticks as a screening test for proteinuria in hypertensive disorders of pregnancy. Hypertension in Pregnancy, 24, 117-123.

GATHIRAM, P. \& MOODLEY, J. (2016). Pre-eclampsia: its pathogenesis and pathophysiolgy. Cardiovascular Journal of Africa, 27, 71.

GELBER, S. E., BRENT, E., REDECHA, P., PERINO, G., TOMLINSON, S., DAVISSON, R. L. \& SALMON, J. E. (2015). Prevention of defective placentation and pregnancy loss by blocking innate immune pathways in a syngeneic model of placental insufficiency. The Journal of Immunology, 195, 1129-1138.

GHIO, A., BERTOlOtTO, A., RESI, V., VOLPE, L. \& DI CIANNI, G. (2011). Triglyceride metabolism in pregnancy. Advances In Clinical Chemistry, 55, 134.

GIRARDI, G (2018). Complement activation, a threat to pregnancy. Seminars in Immunopathology, 40, 103-111. 
GODAHEWA, G. I., PERERA, N. C., BATHIGE, S. D., NAM, B. H., NOH, J. K. \& LEE, J. (2016). Complement factor D homolog involved in the alternative complement pathway of rock bream (Oplegnathus fasciatus): Molecular and functional characterization and immune responsive mRNA expression analysis. Fish Shellfish Immunol, 55, 423-433

GÓMEZ-BANOY, N., GUSEH, J. S., LI, G., RUBIO-NAVARRO, A., CHEN, T., POIRIER, B., PUTZEL, G., ROSSELOT, C., PABÓN, M. A. \& CAMPOREZ, J. P. (2019). Adipsin preserves beta cells in diabetic mice and associates with protection from type 2 diabetes in humans. Nature Medicine, $25,1739-1747$.

GOVENDER, N., NAICKER, T. \& MOODLEY, J. (2013). Maternal imbalance between proangiogenic and anti-angiogenic factors in HIV-infected women with pre-eclampsia. Cardiovascular Journal of Africa, 24, 174.

GRANGER, J. P. (2004). Inflammatory cytokines, vascular function, and hypertension. American Journal of Physiology-Regulatory, Integrative and Comparative Physiology, 286, R989-R990.

GUHA, D. \& AYYAVOO, V. (2013). Innate immune evasion strategies by human immunodeficiency virus type 1. AIDS, 2013, 954806-954806.

HARMAN AC, C. D., AMARAL LM, FAULKNER JL, CUNNINGHAM MW JR, WALLACE K. (2016). Role of inflammation in the Pathology of preeclampsia. Clinical Science, 130, 409-419.

HE, Y., XU, B., SONG, D., YU, F., CHEN, Q. \& ZHAO, M. (2016). Correlations between complement system's activation factors and anti-angiogenesis factors in plasma of patients with early/late-onset severe preeclampsia. Hypertension in Pregnancy, 35, 499-509.

HE, Y. D., XU, B.N., WANG, M.L., WANG, Y.Q., YU, F., CHEN, Q. \& ZHAO, M.H., (2020). dysregulation of complement system during pregnancy in patients with preeclampsia. Molecular Immunology, 122, 69-79.

HELMO, F. R., LOPES, A. M. M., CARNEIRO, A., CAMPOS, C. G., SILVA, P. B., DOS REIS MONTEIRO, M. L. G., ROCHA, L. P., DOS REIS, M. A., ETCHEBEHERE, R. M., MACHADO, J. R. \& CORREA, R. R. M. (2018). Angiogenic and antiangiogenic factors in preeclampsia. Pathology Research Practice, 214, 7-14. 
HLADIK, F. \& MCELRATH, M. J. (2008). Setting the stage: host invasion by HIV. Nature Reviews Immunology, 8, 447-457.

HOFFMAN, M. C., RUMER, K. K., KRAMER, A., LYNCH, A. M. \& WINN, V. D. (2014). Maternal and fetal alternative complement pathway activation in early severe preeclampsia. American Journal of Reproductive Immunology, 71, 55-60.

HOURCADE, D. E. (2006). The role of properdin in the assembly of the alternative pathway C3 convertases of complement. Journal of Biological Chemistry, 281, 2128-2132.

HSU, P. \& NANAN, R. K. H. (2014). Innate and adaptive immune interactions at the fetal-maternal interface in healthy human pregnancy and pre-eclampsia. Frontiers in Immunology, 5, 125.

HUPPERTZ, B., GAUSTER, M., ORENDI, K., KÖNIG, J. \& MOSER, G. (2009). Oxygen as modulator of trophoblast invasion. Journal of Anatomy, 215, 14-20.

ITO K, M. K., UESATO T, SAGO H,OKAMATO A, NAKAZAWA A, HATA K (2015). increased expression of perforin, granzyne B and c5b-9 in villitis of unknown etiology. Placenta, 36, 531537.

JABBOUR, H., SALES, K., CATALANO, R. \& NORMAN, J. (2009). Inflammatory pathways in female reproductive health and disease. Reproduction, 138(6):903-19.

JARVIE, E., HAUGUEL-DE-MOUZON, S., NELSON, SCOTT M., SATTAR, N., CATALANO, PATRICK M. \& FREEMAN, DILYS J. (2010). Lipotoxicity in obese pregnancy and its potential role in adverse pregnancy outcome and obesity in the offspring. Clinical Science, 119, 123-129.

JIANG, T. T., CHATURVEDI, V., ERTELT, J.M., KINDER, J.M., CLARK, D.R., VALENT, A.M., XIN, L. AND WAY, S.S., (2014). Regulatory T cells: a new key for further unlocking the enigma of fetal tolerance and pregnancy complications. The Journal of Immunology, 192, 49494956.

JOLLER, N., WEBER, S. S. \& OXENIUS, A. (2011). Antibody - Fc receptor interactions in protection against intracellular pathogens. European Journal of Immunology, 41, 889-897. 
KALUMBA, V., MOODLEY, J. \& NAIDOO, T. (2013). Is the prevalence of pre-eclampsia affected by HIV/AIDS? A retrospective case-control study. Cardiovascular Journal of Africa, 24, 24.

KEELAN, J. A. \& MITCHELL, M. D. (2007). Placental cytokines and preeclampsia. Frontiers of Bioscience, 12, 2706-2727.

KHARFI, A., GIGUÈRE, Y., SAPIN, V., MASSÉ, J., DASTUGUE, B. \& FOREST, J.-C. (2003). Trophoblastic remodeling in normal and preeclamptic pregnancies: implication of cytokines. Clinical Biochemistry, 36, 323-331.

KILLICK, J., MORISSE, G., SIEGER, D. \& ASTIER, A. L. (2018). Complement as a regulator of adaptive immunity. Seminars in Immunopathology, 40, 37-48.

KLINE, E. R. \& SUTLIFF, R. L. (2008). The roles of HIV-1 proteins and antiretroviral drug therapy in HIV-1-associated endothelial dysfunction. Journal of Investigative Medicine, 56, 752-769.

KUBIS, N. \& LEVY, B. I. (2003). Vasculogenesis and Angiogenesis: Molecular and Cellular Controls:Part 1: Growth Factors. Interventional Neuroradiology, 9, 227-237.

KUSAKABE, K., NAKA, M., ITO, Y., EID, N. \& OTSUKI, Y. (2008). Regulation of natural-killer cell cytotoxicity and enhancement of complement factors in the spontaneously aborted mouse placenta. Fertility and Sterility, 90, 1451-1459.

LANNAMAN, K., ROMERO, R., CHAIWORAPONGSA, T., KIM, Y. M., KORZENIEWSKI, S. J., MAYMON, E., GOMEZ-LOPEZ, N., PANAITESCU, B., HASSAN, S. S. \& YEO, L. (2017). Fetal death: an extreme manifestation of maternal anti-fetal rejection. Journal Of Perinatal Medicine, 45, 851-868.

LANDI, B., BEZZECCHERI, V., GUERRA, B., PIEMONTESE, M., CERVI, F., CECCHI, L., MARGARITO, E., GIANNUBILO, S. R., CIAVATTINI, A. \& TRANQUILLI, A. L. (2014). HIV infection in pregnancy and the risk of gestational hypertension and preeclampsia. World Journal of Cardiovascular Diseases, 4, 257-267.

LARESGOITI-SERVITJE, E., GÓMEZ-LÓPEZ, N. \& OLSON, D. M. (2010). An immunological insight into the origins of pre-eclampsia. Human Reproduction Update, 16, 510-524. 
LE BOUTEILLER, P., LEGRAND-ABRAVANEL, F. \& SOLIER, C. (2003). Soluble HLA-G1 at the materno-foetal interface - a review. Placenta, 24, S10-S15.

LI, H., OHTA, H., TAHARA, Y., NAKAMURA, S., TAGUCHI, K., NAKAGAWA, M., OISHI, Y., GOTO, Y.-I., WADA, K. \& KAGA, M. (2015). Artificial oxygen carriers rescue placental hypoxia and improve fetal development in the rat pre-eclampsia model. Scientific Reports, 5, 15271.

LILLEGARD, K. E., JOHNSON, A. C., LOJOVICH, S. J., BAUER, A. J., MARSH, H. C., GILBERT, J. S. \& REGAL, J. F. (2013). Complement activation is critical for placental ischemia-induced hypertension in the rat. Molecular Immunology, 56, 91-97.

LIU F, D. S., GORDON J, QIN X (2014). complement and HIV-1 infection/HIV-associated neurocognitive disorders. Journal of Neurovirology, 20, 184-198.

LO, J. C., LJUBICIC, S., LEIBIGER, B., KERN, M., LEIBIGER, I. B., MOEDE, T., KELLY, M. E., BHOWMICK, D. C., MURANO, I. \& COHEN, P. (2014). Adipsin is an adipokine that improves $\beta$ cell function in diabetes. Cell, $158,41-53$

LOKKI, A. I., HEIKKINEN-ELORANTA, J., JARVA, H., SAISTO, T., LOKKI, M.-L., LAIVUORI, H. \& MERI, S. (2014). Complement activation and regulation in preeclamptic placenta. Frontiers in Immunology, 5, 312.

LYNCH, A. M., GIBBS, R.S., MURPHY, J.R., BYERRS, T., NEVILLE, M.C., GICLAS, P.C., SALMON, J.E., VAN HECKE, T.M. AND HOLERS, V.M., (2008). Complement activation fragment $\mathrm{Bb}$ in early pregnancy and spontaneous pretermbirth. American Journal of Obstetrics and Gynecology, 199, 354-e351.

LYNCH, A. M. \& SALMON, J. E. (2010). Dysregulated complement activation as a common pathway of injury in preeclampsia and other pregnancy complications. Placenta, 31, 561-567.

LYNCH, A. M., WAGNER, B. D., DETERDING, R. R., GICLAS, P. C., GIBBS, R. S., JANOFF, E. N., HOLERS, V. M. \& SANTORO, N. F. (2016). The relationship of circulating proteins in early pregnancy with preterm birth. American Journal of Obstetrics and Gynecology, 214, 517.e511-517.e518. 
MA, Y., KONG, L. R., GE, Q., LU, Y. Y., HONG, M. N., ZHANG, Y., RUAN, C. C. \& GAO, P. J. (2018). Complement 5a-mediated trophoblasts dysfunction is involved in the development of preeclampsia. Journal Of Cellular And Molecular Medicine, 22, 1034-1046.

MAARTENS, G., CELUM, C. \& LEWIN, S. R. (2014). HIV infection: epidemiology, pathogenesis, treatment, and prevention. The Lancet, 384, 258-271.

MADHUKARAN, S. P., ALHAMLAN, F. S., KALE, K., VATISH, M., MADAN, T. \& KISHORE, U. (2016). Role of collectins and complement protein C1q in pregnancy and parturition. Immunobiology, 221, 1273-1288.

MAHARAJ, N. R., PHULUKDAREE, A., NAGIAH, S., RAMKARAN, P., TILOKE, C. \& CHUTURGOON, A. A. (2017). Pro-Inflammatory Cytokine Levels in HIV Infected and Uninfected Pregnant Women with and without Preeclampsia. PLoS One, 12, e0170063.

MAÎTRE, J. L. (2017). Mechanics of blastocyst morphogenesis. Biology of the Cell, 109, 323-338.

MASLOWSKA, M., VU, H., PHELIS, S., SNIDERMAN, A., RHODE, B., BLANK, D. \& CIANFLONE, K. (1999). Plasma acylation stimulating protein, adipsin and lipids in non-obese and obese populations. European Journal of Clinical Investigation, 29, 679-686.

MAWSON, A. R. (2003). Effects of antiretroviral therapy on occurence of pre-eclampsia. The Lancet, $361,347-348$.

MAYNARD, S. E. \& KARUMANCHI, S. A. (2011). Angiogenic Factors and Preeclampsia. Seminars in Nephrology, 31, 33-46.

MCDONALD, C. R., TRAN, V. \& KAIN, K. C. (2015). Complement activation in placental malaria. Frontiers in Microbiology, 6, 1460.

MCNALLY, R., ALQUDAH, A., OBRADOVIC, D. \& MCCLEMENTS, L. (2017). Elucidating the pathogenesis of pre-eclampsia using in vitro models of spiral uterine artery remodelling. Current Hypertension Reports, 19, 93.

MERLE, N. S., CHURCH, S. E., FREMEAUX-BACCHI, V. \& ROUMENINA, L. T. (2015). Complement system part I-molecular mechanisms of activation and regulation. Frontiers in Immunology, 6, 262. 
MOL, B. W., ROBERTS, C. T., THANGARATINAM, S., MAGEE, L. A., DE GROOT, C. J. \& HOFMEYR, G. J. (2016). Pre-eclampsia. The Lancet, 387, 999-1011.

MOODLEY, J., FAWCUS, S. \& PATTINSON, R. (2018). Improvements in maternal mortality in South Africa. South African Medical Journal, 108, 4-8.

MOODLEY, J., SOMA-PILlAY, P., BUCHMANN, E. \& PATTINSON, R. (2019). Hypertensive disorders in pregnancy: 2019 National guideline. South African Medical Journal, 109.

MORENO-NAVARRETE, J. M. \& FERNÁNDEZ-REAL, J. M. (2019). The complement system is dysfunctional in metabolic disease: Evidences in plasma and adipose tissue from obese and insulin resistant subjects. Seminars in Cell \& Developmental Biology, 85, 164-172.

MORGAN, B. P. \& HOLMES, C. H. (2000). Immunology of reproduction: protecting the placenta. Current Biology, 10, R381-R383.

MUTTER, W. P. \& KARUMANCHI, S. A. (2008). Molecular mechanisms of preeclampsia. Microvascular Research, 75, 1-8.

NAICKER, T., DORSAMY, E., RAMSURAN, D., BURTON, G. J. \& MOODLEY, J. (2013). The role of apoptosis on trophoblast cell invasion in the placental bed of normotensive and preeclamptic pregnancies. Hypertension in Pregnancy, 32, 245-256

NAICKER, T., PHOSWA, W. N., ONYANGUNGA, O. A., GATHIRAM, P. \& MOODLEY, J. (2019). Angiogenesis, Lymphangiogenesis, and the Immune Response in South African Preeclamptic Women Receiving HAART. International Journal Of Molecular Sciences, 20, 3728.

NILSSON, B., HAMAD, O. A., AHLSTRÖM, H., KULLBERG, J., JOHANSSON, L., LINDHAGEN, L., HAENNI, A., EKDAHL, K. N. \& LIND, L. (2014). C3 and C4 are strongly related to adipose tissue variables and cardiovascular risk factors. European Journal of Clinical Investigation, 44, 587-596.

NLOOTO, M. \& NAIDOO, P. (2016). Traditional, complementary and alternative medicine use by HIV patients a decade after public sector antiretroviral therapy roll out in South Africa: a cross sectional study. BMC Complementary And Alternative Medicine, 16, 128. 
NORIS, M. \& REMUZZI, G. (2013) Overview of complement activation and regulation. Seminars in Nephrology, 33, 479-492.

ONYANGUNGA, O., NAICKER, T. \& MOODLEY, J. (2019). Maternal and perinatal outcomes after caesarean delivery in early and late onset preeclampsia with HIV positive and HIV negative South African Women. Nigerian Journal Of Clinical Practice, 22, 591.

OSMAN, I., YOUNG, A., LEDINGHAM, M. A., THOMSON, A. J., JORDAN, F., GREER, I. A. \& NORMAN, J. E. (2003). Leukocyte density and pro-inflammatory cytokine expression in human fetal membranes, decidua, cervix and myometrium before and during labour at term. Basic Science Of Reproductive Medicine, 9, 41-45.

OTUN, H. A., LASH, G. E., INNES, B. A., BULMER, J. N., NARUSE, K., HANNON, T., SEARLE, R. F. \& ROBSON, S. C. (2011). Effect of tumour necrosis factor- $\alpha$ in combination with interferon- $\gamma$ on first trimester extravillous trophoblast invasion. Journal Of Reproductive Immunology, 88, 1-11.

OUCHI, N., PARKER, J. L., LUGUS, J. J. \& WALSH, K. (2011). Adipokines in inflammation and metabolic disease. Nature Reviews Immunology, 11, 85-97

PAYDAS, S., ERGIN, M., SEYDAOGLU, G., ERDOGAN, S. AND YAVUZ, S., (2009). Pronostic significance of angiogenic/lymphangiogenic, anti-apoptotic, inflammatory and viral factors in 88 cases with diffuse large B cell lymphoma and review of the literature. Leukemia Research, 33, 1627-1635.

PEREZ-SEPULVEDA, A., TORRES, M. J., KHOURY, M. \& ILLANES, S. E. (2014). Innate immune system and preeclampsia. Frontiers in Immunology, 5, 244.

PHIPPS, E., PRASANNA, D., BRIMA, W. \& JIM, B. (2016). Preeclampsia: updates in pathogenesis, definitions, and guidelines. Clinical Journal of the American Society of Nephrology, 11, 11021113.

PIERIK, E., PRINS, J. R., VAN GOOR, H., DEKKER, G. A., DAHA, M. R., SEELEN, M. A. \& SCHERJON, S. A. (2019). Dysregulation of complement activation and placental dysfunction: a potential target to treat preeclampsia? Frontiers in Immunology, 10, 3098.

PODOS, S. D., AGARWAL, A. \& HUANG, M. (2018). Chapter 12 - Factor D. In: BARNUM, S. \& SCHEIN, T. (eds.) The Complement FactsBook (Second Edition), 117-126, Academic Press. 
POPKO, K., GORSKA, E., STELMASZCZYK-EMMEL, A., PLYWACZEWSKI, R., STOKLOSA, A., GORECKA, D., PYRZAK, B. \& DEMKOW, U. (2010). Proinflammatory cytokines Il-6 and TNF- $\alpha$ and the development of inflammation in obese subjects. European Journal Of Medical Research, 15, 120.

POSCH, W., LASS-FLÖRL, C. \& WILFLINGSEDER, D. (2011). Innate immune responses in HIVinfection. HIV-Host Interactions, 5, 100-115.

POVEDA, N. E., GARCÉS, M. F., RUIZ-LINARES, C. E., VARÓN, D., VALDERRAMA, S., SANCHEZ, E., CASTIBLANCO-CORTES, A., AGUDELO-ZAPATA, Y., SANDOVALALZATE, H. F., LEAL, L. G., ÁNGEL-MÜLLER, E., RUÍZ-PARRA, A. I., GONZÁLEZCLAVIJO, A. M., DIÉGUEZ, C., NOGUEIRAS, R. \& CAMINOS, J. E. (2016). Serum Adipsin Levels throughout Normal Pregnancy and Preeclampsia. Scientific Reports, 6, 20073-20073.

POWIS, K. M., MCELRATH, T. F., HUGHES, M. D., OGWU, A., SOUDA, S., DATWYLER, S. A., VON WIDENFELT, E., MOYO, S., NÁDAS, M. \& MAKHEMA, J. (2013). High viral load and elevated angiogenic markers associated with increased risk of preeclampsia among Women Initiating Highly Active Antiretroviral Therapy (HAART) in Pregnancy in the Mma Bana Study, Botswana. Journal Of Acquired Immune Deficiency Syndromes, 62, 517.

QING, X., REDECHA, P. B., BURMEISTER, M. A., TOMLINSON, S., D'AGATI, V. D., DAVISSON, R. L. \& SALMON, J. E. (2011). Targeted inhibition of complement activation prevents features of preeclampsia in mice. Kidney International, 79, 331-339.

RAMPERSAD R, B. A., SADOVSKY Y, NELSON DM (2008). The c5b-9 membrane attack complex of complement activation localizes to villous trophoblast injury in vivo and modulates human trophoblast function in vitro. Placenta, 29, 855-861.

REGAL, J. F., BURWICK, R. M. \& FLEMING, S. D. (2017). The complement system and preeclampsia. Current Hypertension Reports, 19, 87.

REGAL, J. F., GILBERT, J. S. \& BURWICK, R. M. (2015). The complement system and adverse pregnancy outcomes. Molecular Immunology, 67, 56-70.

RESHI, P. \& LONE, I. M. (2010). Human immunodeficiency virus and pregnancy. Archives Of Gynecology And Obstetrics, 281, 781-792. 
RICKLIN, D. \& LAMBRIS, J. D. (2013). Complement in immune and inflammatory disorders: pathophysiological mechanisms. The Journal of Immunology, 190, 3831-3838.

ROBERTS, C., WHITE, C., WIEMER, N., RAMSAY, A. \& ROBERTSON, S. 2003. Altered placental development in interleukin-10 null mutant mice. Placenta, 24, S94-S99.

ROBERTS, J. M., BODNAR, L. M., PATRICK, T. E. \& POWERS, R. W. (2011). The Role of Obesity in Preeclampsia. Pregnancy Hypertension, 1, 6-16.

ROBERTS, L., PASSMORE, J.-A. S., WILLIAMSON, C., LITTLE, F., BEBELL, L. M., MLISANA, K., BURGERS, W. A., VAN LOGGERENBERG, F., WALZL, G. \& SIAWAYA, J. F. D. (2010). Plasma cytokine levels during acute HIV-1 infection predict HIV disease progression. AIDS, 24, 819 .

ROMERO, R., ESPINOZA, J., GONÇALVES, L. F., KUSANOVIC, J. P., FRIEL, L. \& HASSAN, S. (2007) The role of inflammation and infection in preterm birth. Seminars In Reproductive Medicine, 25(1): 21-39.

ROSSHEIM AEB, C. T., HAIR PS, SHAN T, ET AL (2016). effects of well controlled HIV infection on complement activation and function. Journal of Acquired Immune Deficiency Syndrome, 73, 20-26.

RUIZ-OJEDA, F. J., OLZA, J., GIL, Á. \& AGUILERA, C. M. (2018). Chapter 1 - Oxidative Stress and Inflammation in Obesity and Metabolic Syndrome. In: DEL MORAL, A. M. \& AGUILERA GARCÍA, C. M. (eds.) Obesity, 1-15, Academic Press.

SAAD, M., SANTOS, A. \& PRADA, P. (2016). Linking gut microbiota and inflammation to obesity and insulin resistance. Physiology, 31(4): 283-293.

SABEN, J., LINDSEY, F., ZHONG, Y., THAKALI, K., BADGER, T. M., ANDRES, A., GOMEZACEVEDO, H. \& SHANKAR, K. (2014). Maternal obesity is associated with a lipotoxic placental environment. Placenta, 35, 171-177.

SAITO, S. \& SAKAI, M. (2003). Th1/Th2 balance in preeclampsia. Journal Of Reproductive Immunology, 59, 161-173. 
SAITO, S., SHIOZAKI, A., SASAKI, Y., NAKASHIMA, A., SHIMA, T. \& ITO, M (2007). Regulatory $\mathrm{T}$ cells and regulatory natural killer (NK) cells play important roles in feto-maternal tolerance. Seminars In Immunopathology, 115-122.

SANSONE, M., SARNO, L., SACCONE, G., BERGHELLA, V., MARUOTTI, G. M., MIGLIUCCI, A., CAPONE, A. \& MARTINELLI, P. (2016). Risk of preeclampsia in human immunodeficiency virus-infected pregnant women. Obstetrics and Gynecology, 127, 1027-1032.

SARGENT, I. L., BORZYCHOWSKI, A. M. \& REDMAN, C. W.(2006). Immunoregulation in normal pregnancy and pre-eclampsia: an overview. Reproductive Biomedicine Online, 13, 680-686.

SCHMIDT, C. Q., LAMBRIS, J. D. \& RICKLIN, D. (2016). Protection of host cells by complement regulators. Immunology Reviews, 274, 152-171.

SIEGFRIED, N., VAN DER MERWE, L., BROCKLEHURST, P. \& SINT, T. T. (2011). Antiretrovirals for reducing the risk of mother-to-child transmission of HIV infection. Cochrane Database Of Systematic Reviews, 7, 1465.

SINGH, J., AHMED, A. \& GIRARDI, G. (2011). Role of complement component C1q in the onset of preeclampsia in mice. Hypertension, 58, 716-724.

SIVAKUMAR, K., BARI, M. F., ADAIKALAKOTESWARI, A., GULLER, S., WEICKERT, M. O., RANDEVA, H. S., GRAMMATOPOULOS, D. K., BASTIE, C. C. \& VATISH, M. (2013). Elevated Fetal Adipsin/Acylation-Stimulating Protein (ASP) in Obese Pregnancy: Novel Placental Secretion via Hofbauer Cells. The Journal of Clinical Endocrinology \& Metabolism, 98, 4113-4122.

SPICER, B. A., LAW, R. H., CARADOC-DAVIES, T. T., EKKEL, S. M., BAYLY-JONES, C., PANG, S.-S., CONROY, P. J., RAMM, G., RADJAINIA, M. \& VENUGOPAL, H. (2018). The first transmembrane region of complement component-9 acts as a brake on its selfassembly. Nature Communications, 9, 1-7.

STAFF, A. C., BENTON, S. J., VON DADELSZEN, P., ROBERTS, J. M., TAYLOR, R. N., POWERS, R. W., CHARNOCK-JONES, D. S. \& REDMAN, C. W. (2013). Redefining preeclampsia using placenta-derived biomarkers. Hypertension, 61, 932-942. 
STAHL, G. L., XU, Y., HAO, L., MILLER, M., BURAS, J. A., FUNG, M. \& ZHAO, H. (2003). Role for the alternative complement pathway in ischemia/reperfusion injury. The American Journal Of Pathology, 162, 449-455.

STATS, SA. (2019) Mid year population estimates 2018. Statistics South Africa.

STEINBERG, G., KHANKIN, E. V. \& KARUMANCHI, S. A. (2009). Angiogenic factors and preeclampsia. Thrombosis Research, 123, S93-S99.

STRAINIC, M. G., SHEVACH, E.M., AN, F., LIN, F. AND MEDOF, M.E., (2013). Absence of signalling into CD4+ cells via C3aR and C5aR enables autoinductive TGF-b1 signalling and induction of Foxp3+ Tregs. Nature Immunology, 14, 162.

SUN, T., LIU, L., WU, A., ZHANG, Y., JIA, X., YIN, L., LU, H. \& ZHANG, L. (2017). iTRAQ based investigation of plasma proteins in HIV infected and HIV/HBV coinfected patients - C9 and KLK are related to HIV/HBV coinfection. International Journal of Infectious Disease, 63, 6471

SUY, A., MARTÍNEZ, E., COLL, O., LONCA, M., PALACIO, M., DE LAZZARI, E., LARROUSSE, M., MILINKOVIC, A., HERNÁNDEZ, S. \& BLANCO, J. L. (2006). Increased risk of preeclampsia and fetal death in HIV-infected pregnant women receiving highly active antiretroviral therapy. Aids, 20, 59-66.

TAKESHITA, A., KONDO, T., OKADA, T. \& KUSAKABE, K. T. (2010). Elevation of adipsin, a complement activating factor, in the mouse placenta during spontaneous abortion. The Journal Of Reproduction And Development, 56, 508-514.

THAN, N. G., EREZ, O., WILDMAN, D. E., TARCA, A. L., EDWIN, S. S., ABBAS, A., HOTRA, J., KUSANOVIC, J. P., GOTSCH, F. \& HASSAN, S. S. (2008). Severe preeclampsia is characterized by increased placental expression of galectin-1. The Journal of Maternal-Fetal \& Neonatal Medicine, 21, 429-442.

THAXTON, J. E. \& SHARMA, S. (2010). Interleukin-10: a multi-faceted agent of pregnancy. American Journal of Reproductive Immunology, 63, 482-491.

TINCANI A, C. I., ZIGLIOLI T, LOJACONO A, DE ANGELIS V, MERONI P (2010). Complement activation and pregnancy failure. Clinical Reviews of Allergy and Immunology, 39, 153-159. 
TOMIMATSU, T., MIMURA, K., ENDO, M., KUMASAWA, K. \& KIMURA, T. (2017). Pathophysiology of preeclampsia: an angiogenic imbalance and long-lasting systemic vascular dysfunction. Hypertension Research, 40, 305-310.

UMAR, A., ORIPELAYE, M., OLANREWAJU, F., ONAYEMI, O., OLASODE, O. \& ONINLA, O. (2020). Determinants of discordant immune response in a cohort of human immunodeficiency virus-infected patients initiating antiretroviral therapy. Sahel Medical Journal, 23, 22-28.

UNAIDS (2020). UNAIDS Global HIV \& AIDS statistics-2020 fact sheet.

VLAICU, S. I., TEGLA, C. A., CUDRICI, C. D., DANOFF, J., MADANI, H., SUGARMAN, A., NICULESCU, F., MIRCEA, P. A., RUS, V. \& RUS, H. (2013). Role of C5b-9 complement complex and response gene to complement-32 (RGC-32) in cancer. Immunologic Research, 56, 109-121.

VON DADELSZEN, P., MAGEE, L. A. \& ROBERTS, J. M. (2003). Subclassification of preeclampsia. Hypertension In Pregnancy, 22, 143-148.

WAGNER, E. \& FRANK, M. M. (2010). Therapeutic potential of complement modulation. Nature Reviews Drug Discovery, 9, 43-56.

WAllace, A. E., FRASER, R., GURUNG, S., GOUlWARA, S. S., Whitley, G. S., JOHNSTONE, A. P. \& CARTWRIGHT, J. E. (2014). Increased angiogenic factor secretion by decidual natural killer cells from pregnancies with high uterine artery resistance alters trophoblast function. Human Reproduction, 29, 652-660.

WANG, T., ZHOU, R., GAO, L., WANG, Y., LIU, X. \& ZHANG, L. (2016). Clinical assessment of the specificity of an adipsin rapid test for the diagnosis of preeclampsia. Hypertension in Pregnancy, 35, 420-425.

WANG, T., ZHOU, R., GAO, L., WANG, Y., SONG, C., GONG, Y., JIA, J., XIONG, W., DAI, L. \& ZHANG, L. (2014). Elevation of urinary adipsin in preeclampsia: correlation with urine protein concentration and the potential use for a rapid diagnostic test. Hypertension, 64, 846-851.

WORLD HEALTH ORGANIZATION. (2019). WHO recommendation Calcium supplementation during pregnancy for the prevention of pre-eclampsia and its complications. [Online]. 
Available: https://apps.who.int/iris/bitstream/handle/10665/277235/9789241550451-eng.pdf [Accessed 4 April 2020]

YU Q, Y. R., QIN X (2010). The good and evil of complement activation in HIV-1 infection. Cellular Mollecular Immunology, 7, 334-340.

ZIPOREN, L., DONIN, N., SHMUSHKOVICH, T., GROSS, A. \& FISHELSON, Z. (2009). Programmed necrotic cell death induced by complement involves a Bid-dependent pathway. The Journal of Immunology, 182, 515-521. 


\section{APPENDIX 1}

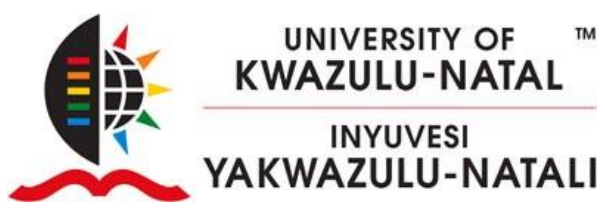

04 June 2020

Prof T Naicker

Discipline of Optics and Imaging

School of Laboratory Medicine and Medical Sciences

naickera@ukzn.ac.za

\section{Dear Prof Naicker}

Title of Project: Exploring the pathogenesis HIV associate pre-eclampsia syndrome in a homogenous South African population group.

BREC Ref No.: BCA338/17

We wish to advise you that your letter received on 20 May 2020 to append the studies below to the above study has now been approved by a sub-committee of the Biomedical Research Ethics Committee

\begin{tabular}{|c|c|c|c|}
\hline MMedSci & Rowen Govender & 215023500 & $\begin{array}{l}\text { The role of complement component } 4 \mathrm{~B}(\mathrm{C} 4 \mathrm{~B}) \text { and complement factor I } \\
(\mathrm{CFI}) \text { in the duality of HIV infected preeclamptic women }\end{array}$ \\
\hline MMedSci & Sumeshree Govender & 21351694 & $\begin{array}{l}\text { The role of } \mathrm{C} 5 \mathrm{a} \text { and } \mathrm{C} 2 \text { protein in pre-eclampsia complicated by } \mathrm{HIV} \\
\text { infection. }\end{array}$ \\
\hline MMedSci & Camille Naicker & 214515577 & $\begin{array}{l}\text { The components } \mathrm{C} 5 \text { and Mannose- binding lectin }(\mathrm{MBL}) \text { functionality in } \\
\text { the complement system in relation to HIV and preeclampsia pregnant } \\
\text { women in Durban, South Africa. }\end{array}$ \\
\hline MMedSci & Mikyle David & 216000603 & $\begin{array}{l}\text { The function of Adipsin and C9 protein in the complement system with } \\
\text { relation to HIV-associated pre-eclampsia }\end{array}$ \\
\hline MMedSci & Tashlin Abel & 215013948 & $\begin{array}{l}\text { The regulation of SLK-1 and SFLT-4 and their involvement in } \\
\text { Preeclamptic woman with HIV. }\end{array}$ \\
\hline MMedSci & Omeshini Naiker & 215028862 & $\begin{array}{l}\text { The role of angiostatin and PDGF in maintaining placental health in } \\
\text { preeclamptic patients }\end{array}$ \\
\hline MMedSci & Nqobile Mdlalose & 216002159 & The role of HER2 and HER 3 in HIV associated preeclampsia \\
\hline MMedSci & Nitalia Naidoo & 216013288 & The role of osteopontin and neuropilin in HIV associated preeclampsia \\
\hline
\end{tabular}

The committee will be notified of the above approval at its next meeting to be held on 14 July 2020.

61 


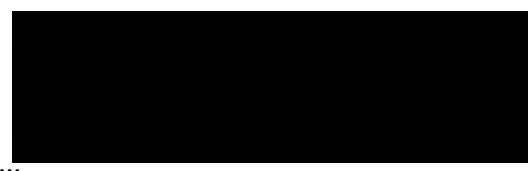

Ms A Marimuthu

(for) Prof D Wassenaar

Chair: Biomedical Research Ethics Committee

Biomedical Research Ethics Committee

Chair: Professor D R Wassenaar

UKZN Research Ethics Office Westville Campus, Govan Mbeki Building Postal Address: Private Bag X54001, Durban 4000

Email: BREC@ukzn.ac.za

Website: http://research.ukzn.ac.za/Research-Ethics/Biomedical-Research-Ethics.aspx 


\section{APPENDIX 2}

Analyte 73

घ Standard Curve Group 1 (... $\square$ Standard Curve Group 1 ○ Control Group 1 O Control Group 2 o Unknown Group 1

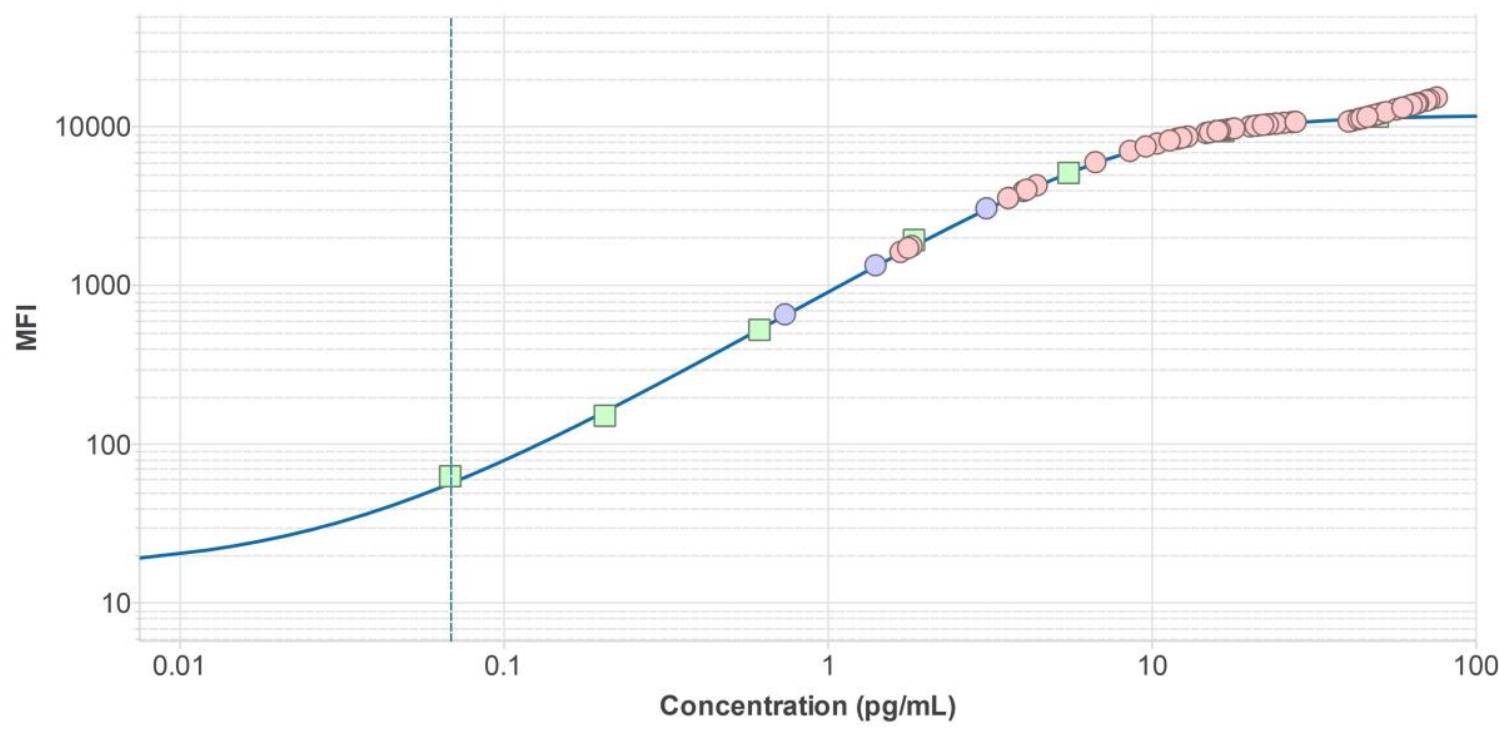




\section{APPENDIX 3}

Analyte 46

घ Standard Curve Group 1 (... $\square$ Standard Curve Group 1 ○ Control Group 1 ○ Control Group 2 o Unknown Group 1

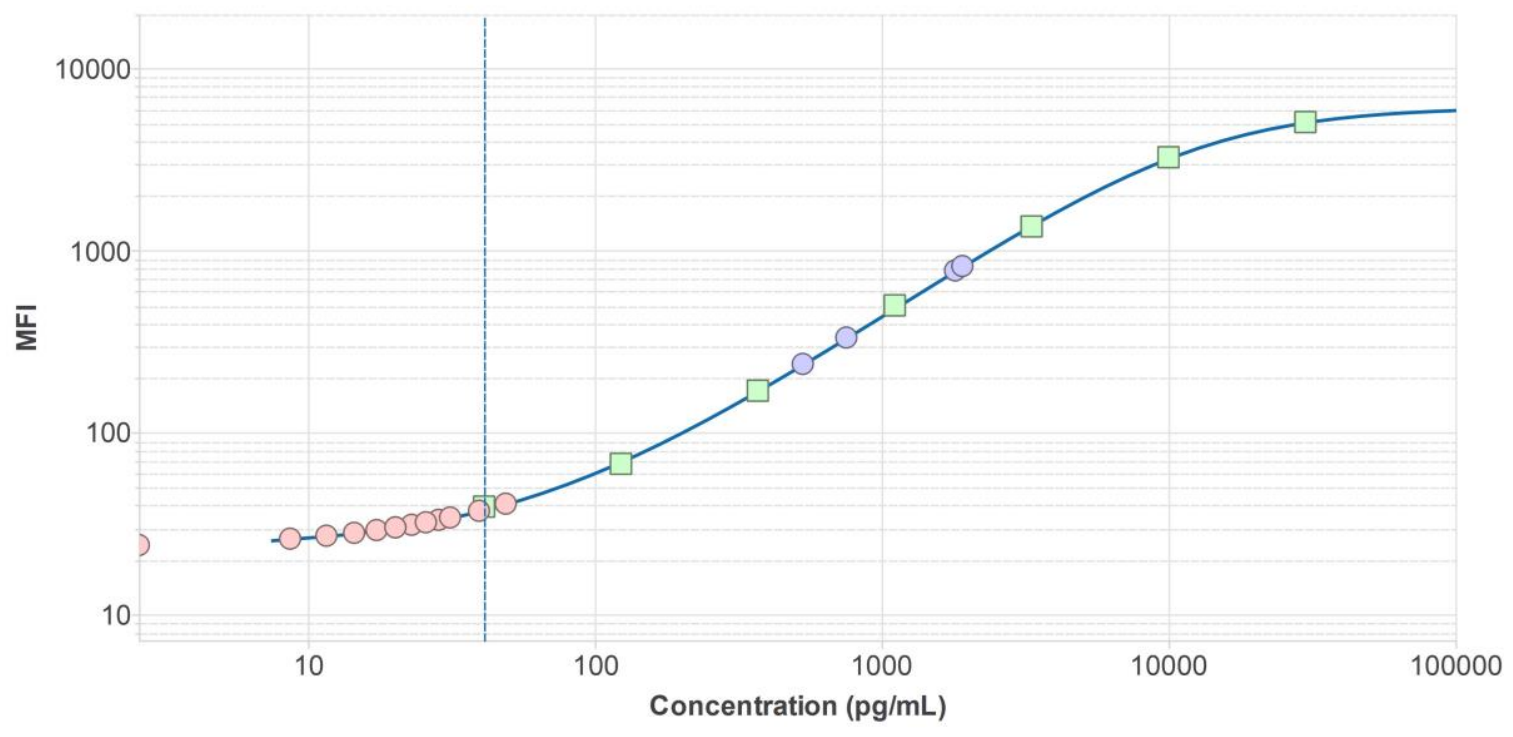

